Culfaz, Eylul. El regimen del bienestar del Sur de Europa y los efectos de la crisis 2007 en el bienestar de España.

\title{
EL REGIMEN DEL BIENESTAR DEL SUR DE EUROPA Y LOS EFECTOS DE LA CRISIS 2007 EN EL BIENESTAR DE ESPAÑA
}

\section{SOUTH EUROPEAN WELFARE REGIMES AND THE IMPACT OF 2007 CRISIS ON SPANISH WELFARE}

\author{
EYLUL CULFAZ \\ Universidad Complutense de Madrid \\ eylultrb@yahoo.com
}

Fecha de recepción: noviembre de 2012

Fecha de aceptación: julio de 2014

\section{RESUMEN}

El presente artículo analiza los países del Sur de Europa (España, Grecia, Italia y Portugal) como partícipes de un modelo específico de bienestar y considera España como el representante del grupo. Con la crisis de 2007, la economía española se ha visto afectada profundamente y también muestra deformaciones en el sistema de bienestar español. El sector privado retrocede en la provisión de bienestar mientras el sector público y las familias asumen en su lugar la mayoría de la carga de la sociedad a través de su sistema de protección social y redes de solidaridad. Pero, tanto las familias -con decrecientes ingresos personales y familiares, y también crecientes tasas de paro- como el estado -con tensiones crecientes sobre sus finanzas públicas- no pueden desempeñar bien su importante papel en el mantenimiento del bienestar, lo que provocará un cambio en el modelo de régimen de bienestar.

PALABRAS CLAVE: régimen del bienestar, Sur de Europa, crisis económicas.

\section{ABSTRACT}

This article analyzes the Southern European countries (Spain, Greece, Italy and Portugal) as participants of a specific model of welfare and considers Spain as representative of the model. As a result of 2007 crisis, the Spanish economy has been affected deeply and also shows deformation in its welfare system. The private sector weakens in providing the welfare while public sector and families take most of the burden of society through the social protection system and solidarity networks. However both families-with decreasing personal and household income, and rising rates of unemployment, and the state-with rising tensions over its public finances, can not fulfill their important role in maintenance of the regime, which can provoke a change in its welfare model.

KEY WORDS: welfare regimes, South Europe, economic crisis.

JEL: I3, I2, I1, P5 
Culfaz, Eylul. El regimen del bienestar del Sur de Europa y los efectos de la crisis 2007 en el bienestar de España.

\section{INTRODUCCIÓN}

El enfoque sobre el bienestar de Esping-Andersen (1990) marcó un hito en los debates académicos acerca de los modelos de bienestar social. En la definición de un sistema o régimen de bienestar, el autor danés incluye diversas esferas de la sociedad además del estado. La idea de identificar elementos significativos para la formación de un sistema de bienestar en el ámbito institucional, cultural y social adquirió gran influencia entre todos aquellos que investigan este tema. Sin embargo, las relaciones que surgen entre las diferentes esferas (mercado, estado, familias y sociedad civil) no siempre consideran los cambios sociales y las transformaciones institucionales propias de los países observados. Por tanto, es importante analizar la evolución de los regímenes de bienestar de acuerdo con el trabajo de EspingAndersen, pero sin renunciar a añadir aquellos aspectos diferenciadores que pudieran aconsejar introducir una nueva tipología en los regímenes de bienestar.

Por bienestar se puede entender todos factores que participan en la calidad de la vida y que hacen que su existencia posea todos los elementos que dan lugar a la satisfacción humana. La satisfacción humana y la calidad de vida son dos condiciones no siempre observables directamente y con un fuerte componente subjetivo para cada individuo. La dificultad de medir el bienestar nos fuerza a delimitar el concepto hacia el campo de las necesidades básicas (alimentación, vivienda, ropa, pero también salud, educación y protección frente a riesgos sociales vinculados a la edad -pensiones- $u$ otras contingencias -incapacidad e invalidez-). En un régimen de bienestar, la satisfacción de dichas necesidades para toda la sociedad es posible distribuyendo toda la carga entre la diferentes esferas: mercado, estado y sociedad civil/ familias- particularmente sobre las mujeres. Las variaciones en esta distribución dan lugar a las diferencias entre los distintos regímenes.

En las dos últimas décadas se ha teorizado mucho acerca de un modelo propio para los países que forman parte del sur Europa (España, Grecia, Italia y Portugal). En este trabajo, se elige a España como país representante del grupo de los países del Sur. Según Andersen, en España el bienestar históricamente ha incorporado algunos de los rasgos más característicos del modelo conservador de la política social. Sin embargo, también se ha desarrollado un modelo incrementalista en materia de servicios sociales y políticas de ingresos, junto algunas prácticas corporativistas heredadas de épocas anteriores. Así, pues, el régimen de bienestar español puede ser considerado como una vía intermedia en comparación con otros sistemas de protección social. El desarrollo de este trabajo de investigación descansa sobre esta hipótesis. El sistema de bienestar español (al igual que sucede en otros países del sur de Europa) presenta tanto características de los regímenes "bismarckianos" como de los "beveridgeanos", o más bien, se sitúa entre el modelo continental de "hombre-sostén" y el modelo liberal. También representa una posición intermedia en lo referido a las tensiones entre la mercantilización y la generalización de los derechos sociales (y el acceso universal a los medios para su materialización).

Con la crisis económica desatada en 2007, la economía española se ha visto afectada profundamente. Ahora bien, la repercusión de la crisis no se limita a la economía. Ha causado también deformaciones en el sistema de bienestar español. Por un lado, el sector privado retrocede en la provisión de bienestar mientras el 
Culfaz, Eylul. El regimen del bienestar del Sur de Europa y los efectos de la crisis 2007 en el bienestar de España.

sector público y las familias asumen en su lugar la mayoría de la carga de la sociedad a través de su sistema de protección social y redes de solidaridad. Pero, por otro lado, tanto las familias -con decrecientes ingresos personales y familiares, y también crecientes tasas de paro- como el estado -con tensiones crecientes sobre sus finanzas públicas- no pueden desempeñar bien su importante papel en el mantenimiento del bienestar, por lo que cabe afirmar que la crisis económica es también en buena medida una crisis del régimen de bienestar.

En este trabajo, la primera hipótesis es; hay un régimen de bienestar específico que existe en los países del Sur de Europa y este régimen se puede referir al cuarto tipo en la tipología de Esping-Andersen. Las características peculiares al régimen del Sur de Europa se pueden determinar por mirando a la estructura del mercado laboral, al gasto público en el materia social y al papel de las familias en el mantenimiento del bienestar. Representación del régimen del Sur de Europa a través de los datos de España es nuestra segunda hipótesis. España, con otros tres; Grecia, Portugal e Italia lleva las características de este tipo de régimen y en este trabajo esta utilizado como un ejemplo para esta agrupación. Como última hipótesis, el impacto de la última crisis sobre las áreas que determinan el carácter del dicho régimen es crucial y es posible causar un cambio en la tipología. Esta hipótesis, nos lleva a las preguntas para los trabajos futuros.

Metodológicamente, esta investigación se encuentra a mitad de camino entre un análisis de datos y un estudio de literatura comparada. Resulta útil el uso de los datos para entender las clasificaciones ya asentadas de los regímenes del bienestar, pero es imprescindible combinar y completar el análisis cuantitativo con un marco teórico interpretativo. Asimismo, resulta necesario situar el análisis en su contexto, lo que justifica que se haya introducido un último capítulo sobre los efectos de la crisis en algunos de los componentes más importantes del bienestar social en España.

\section{EL MODELO DEL RÉGIMEN DE BIENESTAR EN EL SUR DE EUROPA}

A partir de la década de los 90 s, el régimen de bienestar en los países del Sur de Europa se ha convertido en una cuestión de interés académico en la medida en que se ha empezado a considerar como un modelo distinto de los tres modelos canónicos que plantea Esping-Andersen en su obra clásica Three Worlds of Welfare Capitalism (1990). La tipología de Esping-Andersen surge de considerar las diferentes combinaciones de derechos sociales y estratificaciones de los estados de bienestar que están presentes en varios países. Un primer modelo es el régimen liberal, cuyas características fundamentales son la existencia de unas transferencias universales muy modestas y un sistema de seguridad social también muy moderado. El estado en este primer modelo no provee una gama amplia de derechos sociales y crea una estratificación entre sus beneficiarios de diferentes clases; en dicho régimen, se da una mínima des-mercantilización (decommodification) de la fuerza de trabajo. Los principales países en lo que está vigente este modelo son Estados Unidos, Canadá y Australia. El segundo modelo, al que llama Andersen "tipo corporativista", o en algunos casos "modelo conservador", incluye a Italia, Francia, Alemania y Austria. En dichos países, los derechos se relacionan con el status económico y social y, naturalmente, lo que importa es preservar las diferencias de condiciones sociales. En este régimen de bienestar el Estado tiene un papel más importante sobre la des-mercantilización de la fuerza de trabajo que en el modelo 
Culfaz, Eylul. El regimen del bienestar del Sur de Europa y los efectos de la crisis 2007 en el bienestar de España.

anterior, pero su función redistributiva es limitada. Un carácter común de los países que participan de este modelo es su orientación conservadora y la importancia de la iglesia y la institución familiar es significativa. Por último, Esping- Andersen se refiere, como un tercer modelo, al régimen universalista. Las prestaciones sociales están extendidas a la clase media de una manera adecuada para el mantenimiento de su nivel de vida y, naturalmente, evitan el dualismo entre el mercado y Estado. Los países escandinavos son representantes de este grupo.

Aparte de la tipología de Esping-Andersen, podemos considerar otro tipo de clasificación que diferencia entre los regímenes Bismarckianos y Beveridgianos. El «sistema bismarckiano» se caracteriza a partir de las leyes que, sobre los seguros de salud, los accidentes laborales y los seguros de discapacidad y jubilación, entraron en vigor en Alemania a finales del siglo XIX durante el periodo de Bismarck. También se llama a dicho régimen «sistema categórico», por categorizar la sociedad en grupos ocupacionales y organizar el sistema de seguridad social según el principio del trabajo mercantil. El financiamiento del sistema lo proporcionan los propios beneficiarios, o en otras palabras, los propios asalariados, por lo que se organiza y funciona en torno al principio de reciprocidad de manera que, efectivamente, no siempre es posible extender a toda la sociedad el sistema de protección social.

Por otro lado, los «sistemas beveridgianos» surgen de las teorías de William Beveridge, quien trabajó en la Comisión de la Reforma en la Asistencia Pública en los años 1930s y 40s en Inglaterra. El objetivo principal de la seguridad social -según Beveridge- es garantizar tanto las necesidades básicas como también los ingresos regulares de la población asalariada. Aquel aspecto que amenaza el mantenimiento de los ingresos regulares de los trabajadores es considerado y calificado como "riesgo social", y el sistema de seguridad social debería proteger a los asalariados de ellos. Sin embargo, la parte no asalariada de la sociedad también debería estar cubierta por el sistema de protección social con los programas de asistencia social. En consecuencia, este sistema abraza a todas las personas con independencia de su situación laboral y cubre todos los riesgos que puede poner en peligro los ingresos.

La Europa del bienestar mediterráneo puede ser considerada una "vía media"1 de los dos regímenes, por ocupar un sitio intermedio entre el régimen bismarckiano (el cual sirve principalmente para el mantenimiento de rentas ocupacionales) y el régimen beveridgeano (que permiten una cobertura universalista).

Generalmente, el debate gira alrededor de si el tipo del bienestar "mediterráneo" forma un grupo particular y diferenciado de los tres modelos anteriormente reseñados o es sólo un modelo de "fleco latino", 2 refiriéndose con ello a un nivel rudimentario de protección social (Leibfried, 1992; Gough, 1996). No obstante, esta cuestión se sigue debatiendo todavía en el inicio de este siglo XXI. Hay discrepancias acerca de si los cuatros países pueden formar "un Capitalismo de

\footnotetext{
1 Moreno Luis, "La vía media española del modelo de bienestar mediterráneo", Consejo Superior de Investigaciones Cientificas, Papers 63/64, 2001; p: 70

2 Moreno Luis, "La vía media española del modelo de bienestar mediterráneo", Consejo Superior de Investigaciones Cientificas, Papers 63/64, 2001; p: 70
}

Papeles de Europa 
Culfaz, Eylul. El regimen del bienestar del Sur de Europa y los efectos de la crisis 2007 en el bienestar de España.

Bienestar del Cuarto Mundo", esto es, una cuarta tipología en los regímenes de bienestar, o si sólo representan un sub-categoría del "régimen del bienestar conservador" en un nivel inferior. Aparte de las características del régimen corporatista/conservador que hemos mencionado más arriba, el familiarísimo es el punto de enfoque que centra este debate. Cuando decimos familiarismo, a lo que nos estamos refiriendo es a la centralidad de las familias como cuidadoras y como lugares de solidaridad y provisión del bienestar. Además, aunque vamos a profundizar las diferentes propuestas sobre el tema más adelante, el familiarismo puede conllevar el sesgo del modelo familiar del hombre-sostén (male breadwinner) en la protección social (Karamessini, 2007).

Efectivamente, los cuatro países del Sur de Europa comparten algunas características comunes relacionadas con su historia, sistemas de valores y estructuras de relación entre el estado, el mercado y las familias.

\subsection{Rasgos comunes del régimen de bienestar del sur de Europa}

De manera general, el rasgo más aparente, compartido por los países del Sur, es su escasez de recursos para subsidiar las políticas sociales. Este rasgo se puede relacionar con un desarrollo económico tardío, pero rápido, y también con el carácter exitoso en el área del cambio social. Naturalmente, la falta de recursos financieros puede ser un factor importante para explicar la situación pero no sirve para una explicación completa de este régimen de bienestar.

Un grupo de los autores, que incluye a Esping-Andersen (1990), considera los países de Sur de Europa como una variante del régimen conservador con unas características familiaristas más fuertes que en otros países de mismo régimen y también con un sistema de protección social menos eficiente y menos maduro. Por otro lado, autores como Ferrera (1996) defienden un modelo distinto para los países mediterráneos de Europa, aunque cada uno tenga sus propias peculiaridades. Aparte del papel central de la Iglesia y la familia en dichos países, Ferrera señala más rasgos: una fragmentación alta y una polarización interna en el programa de mantenimiento de los ingresos, una ruptura desde la tradición corporativa a través de una sistema de salud universal y una distribución selectiva de las prestaciones monetarias a través de clientelismo y las redes clientelares.

Los debates sobre la universalidad y la selectividad se han relacionado con las cuestiones de equidad y redistribución de los servicios sociales. Hay una controversia sobre la cuestión de si la focalización (targetting) es para una redistribución más igualitaria o no. Un punto de vista sostiene que, en términos generales, el gasto público en salud, educación, vivienda y transporte sistemáticamente favorece a los más ricos en detrimento de los ciudadanos que necesita tener acceso a esos servicios (Le Grand, 1982). Por lo tanto un criterio de selectividad deberían establecerse para hacer frente a los grupos menos favorecidos de la sociedad. Otro punto de vista reconoce que la clase media se ve favorecida en el estado universal de bienestar. Sin embargo, en el largo plazo, este resultado estimula la formación de la coalición entre la clase obrera y la clase media para la continuación de las políticas del estado de bienestar (Korpi, 1980; Pzeworski, 1985). En el caso de un estado de bienestar universal como Suecia, no existe evidencia de que las clases medias se ven favorecidas por las instituciones del Estado 
Culfaz, Eylul. El regimen del bienestar del Sur de Europa y los efectos de la crisis 2007 en el bienestar de España.

(Söderström, 1988). Sin embargo, y una vez que las transferencias fiscales se han tenido en cuenta, el $60 \%$ de los hogares pagan más y reciben mucho menos del sistema de seguro social (Andersen, 1999).

La situación en el sur de Europa corre a la dirección opuesta de algunas reformas tomados por escandinavos. De hecho, a partir de un sistema contributivo de seguridad social donde la selectividad ha sido el rector principal del desarrollo del bienestar, en Sur una tendencia reciente hacia la universalización de beneficios y servicios está consolidando. En el centro de la discusión se encuentra la controversia relacionada con el llamado "Efecto Mateo" (Matthew Effect), que tiene consecuencias en el caso del bienestar del Sur de Europa. Este efecto proporciona ventajas desproporcionadas para las personas con los recursos de información sobre aquellos que tienen derecho a las prestaciones, pero faltan de conocimientos técnicos y red de clientelismo. Sin embargo, en contrario de otros sistemas europeos, las políticas llevadas de focalización en el sur de Europa, tuvieron un efecto dominó sobre desfavorecidas; ampliando las "zonas grises" entre ámbitos de seguridad social y de asistencia social. Hay varias razones de tal fenómeno pero relacionado con este trabajo podemos relacionarlo con el papel de la economía informal y de la familia mediterránea.

Los factores centrales que nos permiten caracterizar a los países del Sur se corresponden con tres ámbitos fundamentales: 1) la estructura del mercado laboral, 2) la estructura del Estado del bienestar, desde el punto de vista del gasto público en materia social, y 3) la estructura social, particularmente el papel de las familias.

\subsubsection{Estructura del mercado laboral}

Varios estudios sobre la estructura del mercado laboral señalan suficientes semejanzas en Italia, Grecia, España y Portugal en relación con la regulación del desempleo y la distribución de las responsabilidades entre el estado, mercado y familias como para considerar la existencia de un modelo común de base familiarista (Gallie y Paugam, 2000). La baja tasa de empleo de las mujeres en el mercado laboral, la alta institucionalización del matrimonio, la larga duración de la convivencia de los jóvenes con sus familias y las obligaciones que surgen de las relaciones entre generaciones son otras características que podemos incluir como resultados de varios estudios comparativos (Guerrero y Naldini ,1997).

También al analizar la estructura del mercado laboral es posible notar los puntos comunes. Los países de Europa meridional cuenta con una relativamente alta participación de la agricultura en el conjunto del empleo, las tasas del empleo por cuenta propia son las más altas del promedio de la UE, la participación de las mujeres en el trabajo mercantil -salvando el caso de Portugal- es baja, la presencia de empleos a tiempo parcial es menor que en otros a países de la Unión, las tasas del desempleo entre jóvenes son más altas que en el resto de la población empleada y, por último, la alta segmentación del mercado laboral según diferentes categorías -tal como la edad, el sexo, el origen étnico, el sector privado/publico o el sector formal/informal (Karamessini, 2007).

Al considerar los rasgos políticos, sociales y económicos desde una perspectiva histórica, algunos autores concluyen que Italia, España, Portugal y Grecia tienen un

Papeles de Europa

Vol. 27, Núm. 1 (2014): 105-136

http://dx.doi.org/10.5209/rev_PADE.2014.v27.n1.47014 
Culfaz, Eylul. El regimen del bienestar del Sur de Europa y los efectos de la crisis 2007 en el bienestar de España.

mismo proceso de desarrollo capitalista, un desarrollo que se corresponde con el típico de los países de la industrialización tardía. Efectivamente, la mayoría de los países mediterráneos siguieron un proceso del desarrollo lento pero apreciable, especialmente sensible a los riesgos sociales del primer orden (first order social risks), que se pueden definir como aquellos riesgos frente a los que una familia no puede defenderse suficientemente. Como señala Trifiletti, el riesgo de muerte o el riesgo de perder un trabajo estable, en vez de ser percibidos como riesgos individuales, son percibidos como riesgos que puede dañar la capacidad de las familias para seguir funcionando como antes. Ello es así porque las familias en los países mediterráneos funcionan como una pequeña empresa, de manera que su estrategia es intentar producir un ingreso total y suficiente para mantener a todos sus miembros y cubrir los riesgos sociales de todos ellos (Trifileti, 1995).

El papel desempeñado por la economía informal es importante en la formación del bienestar del sur de Europa, sobre todo si se tiene en cuenta el llamado "efecto Mateo" cual está definido arriba. Según el reporte de la Comisión Europea del año 2007, los países del Sur de Europa tienen algunas características diferentes del resto de Europa. Las estadísticas en el reporte indican que algunos países del Sur de Europa; España y Portugal, muestran un nivel más bajo que el promedio Europeo, en la expropiación del "trabajo no declarado". (European Commission, 10) ${ }^{3}$ Además, mirando a los datos del reporte, la provisión de los trabajos informales en números de personas, también refleja un nivel bajo del promedio. (lbid, 18) ${ }^{4}$ in embargo, cuando los comparamos con los datos de las horas llevadas en un trabajo no declarado; podemos ver que el grupo de los países del Sur de Europa muestra mayor nivel en Europa. Esto indica que los trabajadores informales en otros partes de Europa suelen ser una actividad complementaria; mientras en el Sur de Europa, tienen una forma de más significativa como una necesidad natural. (lbid, 20) ${ }^{5}$. Esto se traduce en una distribución desigual de las cargas financieras a través de los diversos grupos ocupacionales. Contribuyentes honestos y necesitados son penalizados, y aquellos otros que evaden o no contribuyen sin embargo salen beneficiados. El objetivo de los trabajadores informales es maximizar, principalmente, de los programas de selectividad no contributivos basados en la comprobación de medios. Algunos de ellos, sin embargo, se abstienen de hacerlo a causa de la "estigmatización", un comportamiento cultural, ampliamente extendido, en el sur de Europa (Moreno, 1998).

\footnotetext{
${ }^{3}$ La Comisión Europea hizo una encuesta para evaluar el tamaño de la economía informal en Europa. Dividiendo el trabajo entre dos partes; la expropiación del trabajo informal y su provisión; preguntaron algunas preguntas a los encuestados. Los resultados muestran que el promedio Europeo en el número de las personas que indicaron que habían adquirido unos bienes y servicios que contienen trabajo informal, es 11\%. España, Grecia, Italia y Portugal respectivamente tienen $6 \%, 17 \%, 12 \%$ y 7\%. (European Commission 2007, p.10)

${ }^{4}$ Según los datos del reporte de la Comisión Europea, el promedio Europeo en el número de las personas que indicaron que habían participado en un trabajo informal, es 5\%. España, Grecia, Italia y Portugal respectivamente tienen $3 \%, 4 \%, 3 \%$ y $3 \%$.

${ }^{5}$ No obstante, hay varias interpretaciones sobre la diferencia entre las respuestas de los encuestados y sus participaciones reales. Primero, hay formas del trabajo no declarado tan comunes que no están percibidos como informales. El nivel de la prosecución de la economía informal cambia depende del país y como la ultima, también, la tolerancia del público con relación a los trabajadores ilegales varia. Por estas razones, los resultados no se pueden reflejar los resultados correctos definitivamente. (European Commission,18)
}

Papeles de Europa 
Culfaz, Eylul. El regimen del bienestar del Sur de Europa y los efectos de la crisis 2007 en el bienestar de España.

\subsubsection{Gasto público en materia social}

El gasto público en protección social como porcentaje del PIB en los países del sur de Europa muestra unos resultados por debajo del promedio europeo. ${ }^{6}$ Según los datos de "Population and Social Conditions" por Antonella en Eurostat, en el año 1996, el promedio de la Unión Europa en el gasto social era de $28,7 \%$ del PIB y el mismo indicador para Grecia era un 23,3\%, en España 22,4\%, para Italia 24,8\% y para Portugal $21,6 \%$. Trece años después, la situación muestra cambios significativos y la brecha de los países del Sur son el promedio disminuye sustancialmente sin embargo todavía quedan por debajo del promedio europeo. En 2009 , el promedio de la Unión Europa en gasto social era $29,5 \%$ del PIB y los de Grecia, Portugal, España e Italia eran, respectivamente, 27,6\%, 26,9\%, 25\% y $29,8 \%$; en ese mismo año, el promedio de la UE-27 en gasto per cápita también era más alto que el de los cuatro países. No obstante, cabe observar que Italia superó el promedio europeo (desviándose de los otros países del Sur), pero que todavía sigue en mismo grupo cuando comparamos el gasto social per cápita.

La situación resulta mucho más interesante cuando miramos la composición de ese gasto. Las diferencias no sólo están entre el sur y el norte de Europa, sino también entre los propios países del Sur. Si, como hace Eurostat, desagregamos el total del gasto social en ocho grupos: 1) protección social ante la vejez, 2) enfermedad, 3) discapacidad, 4) exclusión social, 5) desempleo, 6) gasto social para las familias y los hijos, 7) para la supervivencia y, por último, 8) vivienda, podremos ver las peculiaridades en la distribución del gasto entre los países del Sur.

En el cuadro 1, se ven las diferencias en la distribución de las diferentes funciones del gasto social que existen entre países. Según los datos de 2009 de Eurostat, la protección ante la vejez y la enfermedad son, con carácter general, las partidas que tienen un mayor peso dentro del gasto total, con el $37,6 \%$ y $29,5 \%$, respectivamente. Los gastos para las familias y los discapacitados ocupan como el tercero y el cuarto lugar, y el desempleo viene en el sexto lugar (en apartados siguientes, vamos a ver como esto había cambiado sustancialmente en la actualidad con la crisis). En Italia, las pensiones para las jubilaciones tienen mayor peso, con 14,4\% del PIB, mientras que mismo indicador ocupa solo el 7,6\% del PIB en el caso de España, dos veces menos que la proporción italiana. En 2009, en España, el 3,6\% del PIB va al gasto social para la protección ante el desempleo, mientras en Italia, es 0,7\%.

Los datos del cuadro 1 permiten asimismo la comparación entre países pertenecientes a diferentes regímenes del bienestar. Se pueden comprobar claramente las diferencias. En Alemania y Francia, dos países típicos del régimen «bismarckiano», el gasto social total tiene un porcentaje mucho más alto que el Sur de Europa, siendo también más elevado que el promedio europeo. Incluso, Reino Unido -representante del régimen liberal del bienestar- tiene una proporción más alta que los países del Sur del Europa en el gasto social total (salvando otra vez el caso italiano). Hay que resaltar, mirando el gasto por desempleo, el enorme peso que adquiere en España dado el elevado nivel de desempleo que padece la economía de este país.

\footnotetext{
${ }^{6}$ Puglia Antonella, "Population and Social Conditions", Eurostat, Statistics in Focus 17/ 2001.

Papeles de Europa 
Culfaz, Eylul. El regimen del bienestar del Sur de Europa y los efectos de la crisis 2007 en el bienestar de España.

Cuadro 1. La Distribución del Gasto Social

\begin{tabular}{|l|c|c|c|c|c|c|c|c|c|c|}
\hline $\begin{array}{l}\text { 2009_- } \\
\text { \%PIB }\end{array}$ & $\begin{array}{c}\text { Gasto } \\
\text { Social } \\
\text { Total }\end{array}$ & Salud & $\begin{array}{c}\text { Discapa } \\
\text { cidad }\end{array}$ & Vejez & $\begin{array}{c}\text { Supervi } \\
\text { vientes }\end{array}$ & Familia & $\begin{array}{c}\text { Desemp } \\
\text { leo }\end{array}$ & Vivienda & $\begin{array}{c}\text { Exclusión } \\
\text { Social }\end{array}$ & $\begin{array}{c}\text { Educaci } \\
\text { ón }\end{array}$ \\
\hline UE-27 & 29,51 & 8,39 & 2,26 & 11,05 & 1,70 & 2,27 & 1,72 & 0,57 & 0,41 & 5,41 \\
\hline Grecia & 27,97 & 7,95 & 1,29 & 11,29 & 2,24 & 1,83 & 1,61 & 0,50 & 0,58 & \\
\hline España & 25,04 & 7,30 & 1,72 & 7,66 & 2,16 & 1,51 & 3,67 & 0,20 & 0,27 & 5,01 \\
\hline Italia & 29,82 & 7,31 & 1,74 & 14,44 & 2,64 & 1,40 & 0,80 & 0,02 & 0,07 & 4,7 \\
\hline Portugal & 26,94 & 7,27 & 2,16 & 11,15 & 1,83 & 1,49 & 1,36 & 0,00 & 0,34 & 5,79 \\
\hline Alemania & 31,38 & 9,66 & 2,43 & 9,97 & 2,16 & 3,17 & 1,90 & 0,65 & 0,18 & 5,06 \\
\hline Francia & 33,06 & 9,38 & 1,87 & 12,40 & 2,01 & 2,65 & 1,93 & 0,85 & 0,56 & 5,89 \\
\hline $\begin{array}{l}\text { Reino } \\
\text { Unido }\end{array}$ & 29,20 & 8,67 & 2,98 & 12,00 & 0,16 & 1,82 & 0,84 & 1,47 & 0,22 & 5,67 \\
\hline
\end{tabular}

Fuente: Eurostat, 2009 (online data code: spr_exp_sum)

La base de datos de Eurostat no incluye educación como un ingrediente dentro del gasto social por eso no está incorporado en la columna de "gasto social total". Sin embargo, podemos considerarlo perfectamente como parte del mismo por su contribución a la igualdad de oportunidades y su función niveladora. En el cuadro 1, en la última columna, podemos ver el porcentaje del gasto público- no es del gasto social- en educación dentro del PIB según los datos de Eurostat. Aunque no se encuentran datos para Grecia, comparando los datos de España e Italia con el promedio europeo ( $\mathrm{y}$ también con los otros tres países se puede comprobar que la importancia del gasto público en educación es menor en el sur de Europa. Sin embargo, en el caso de Portugal (5,79\% del PIB en educación) se sobrepasa el promedio europeo, e incluso las proporciones de Alemania y Reino Unido.

Otra característica común de la estructura del gasto social de Grecia, Italia, España y Portugal, es el nivel de fragmentación de la protección social según las líneas ocupacionales, particularmente en el caso griego. Un ejemplo representativo de ello son los mecanismos de aseguramiento presentes en el sistema de salud. El sistema griego está formado por un mosaico de fondos de seguro médico donde ni los requisitos ni los beneficios presentan rasgos homogéneos. La estructura de los seguros en España e Italia también muestra una fragmentación en un nivel significativo (Ferrera, 1996). Además, la combinación del sistema de salud universalista con los planos profesionales de pensiones es el típico resultado de ser una "vía media" entre regímenes bismarckianos y beveridgeanos.

\subsubsection{El papel de las familias}

Si hablamos del bienestar del Sur de Europa es fundamental no olvidar el papel relevante que desempeña la institución familiar en la protección social. En el sur de Europa, el régimen de bienestar es en gran medida el bienestar que proporciona la familia mediterránea. En el interior de las familias, las transferencias son tanto materiales como inmateriales. Respecto a esta última, la participación de las mujeres en el cuidado de los ancianos y niños es crucial. Sin embargo, la creciente participación de las mujeres trabajadoras en el mercado laboral, junto con las nuevas cargas que surgen a la hora de la formación de la familia, plantean cuestiones importantes, como la de si el bienestar del sur puede sobrevivir tal y 
Culfaz, Eylul. El regimen del bienestar del Sur de Europa y los efectos de la crisis 2007 en el bienestar de España.

como lo conocemos en la actualidad. En la actualidad se percibe claramente la tendencia en estos países a apartarse de la funcionalidad tradicional de la familia como complemento indispensable de la acción del estado de bienestar y la transición hacia una modalidad más universal en el sistema de servicios sociales y prestaciones. Otros cambios, sin embargo, aún no se han contrastado.

En este sentido, cabe mencionar la tipología de regímenes del bienestar que ha hecho Jane Lewis (1989) comparando la dimensión discriminativa del género en los diferentes modelos de bienestar. Esta tipología es especialmente oportuna para mostrar la fragmentación por motivos de género en las políticas sociales de los países mediterráneos. Aunque una persona por su propia cuenta, no podría proporcionar una vida decente, eso podría ser posible si se juntan dentro de un ingreso familiar que incluye otros ingresos parciales de agricultura, trabajo por cuenta propia, de producción propia de servicios o productos de cosecha propia, en "synthesis of breadcrumbs". . En ese manera, pueden cumplirse todas las necesidades de los miembros de la familia a través de juntar los ingresos de diferentes recursos. El ingreso familiar, en vez de personal, destaca el papel de las familias en los países mediterráneos, diferenciándose de este modo del modelo clásico del hombre-sostén.

En la figura 1, el eje vertical representa el grado de protección que ofrece el Estado a las mujeres frente al mercado y muestra, en sus extremos, dos tipos de regímenes: uno de protección y otro de desprotección frente a los riegos vinculados al mercado. El eje horizontal, a su vez, muestra otra diferenciación entre regímenes de bienestar al incorporar las percepciones que desde el estado se tienen del papel y la función a desempeñar por las mujeres. Del cruce de ambos ejes, surge una tipología que se corresponde con los cuatro cuadrantes resultantes. El primero y tercero muestran los regímenes de máxima discriminación por motivos de género, y el segundo y cuarto cuadro de la figura muestran los regímenes con mínima discriminación de las mujeres.

Empezando con los que ejercen una mínima discriminación, en el segundo cuadro el modelo del bienestar universalista- el estado trata a las mujeres principalmente como trabajadoras, las protege en el mercado de trabajo en función de su papel de madres, apunta a la igualdad real de oportunidades y no ejerce ningún control sobre su pago y trabajo no remunerado. Aquí, las mujeres que trabajan, bien a tiempo parcial o bien a tiempo completo, tienen en ambos casos acceso a prestaciones y servicios sobre la base de su condición de trabajadoras. En caso de necesidad, la cuestión su estado civil derivada de ellos. Sólo en este régimen es posible que el estado pueda sostener y sustituir el trabajo de cuidado, sin dañar el trabajo remunerado de las mujeres.

En el modelo liberal, el estado trata a las mujeres principalmente como trabajadoras pero no las garantiza protección frente a los riesgos derivados del mercado, ignora sus roles familiares, excepto en caso de la pobreza extrema, ejerce sólo un control indirecto económico sobre su trabajo mercantil y ofrece servicios sociales escasos dotación. EEUU, Australia y Gran Bretaña están colocados en este tipo del modelo del bienestar.

\footnotetext{
${ }^{7}$ Triffiletti R., Welfare Regimes and the Worsening Position of Women; p:53.

Papeles de Europa 
Culfaz, Eylul. El regimen del bienestar del Sur de Europa y los efectos de la crisis 2007 en el bienestar de España.

Lo que resulta más importante para este trabajo es la diferencia entre el modelo del «hombre-sostén» y el modelo «mediterráneo». Si el estado trata a las mujeres principalmente sobre la base de sus roles familiares y las protege en el mercado, eso significaría que el estado ejerce un control sobre el trabajo no remunerado de las mujeres, profundizando de este modo la discriminaciones de género en el mercado laboral. Este es el modelo del hombre-sostén, donde el varón aparece como sustentador principal de la familia. Es el régimen clásico de Alemania, Gran Bretaña, Irlanda en el que las mujeres trabajan en su mayoría a tiempo parcial y reciben los beneficios sociales a través de sus maridos. En otro lado, si el estado trata a las mujeres principalmente sobre la base de sus roles familiares y tampoco les protege en el mercado de trabajo; eso significaría que en cierto sentido, el estado ejerce un control sobre ambos tipos del trabajo -remunerado y no remunerado- de las mujeres; porque faltan las disposiciones mínimas en el mercado de trabajo y también el trabajo de cuidado se da por sentado por parte de la sociedad. Es el caso de la mayoría de los países del Mediterráneo -Italia, España y Grecia. La participación de las mujeres en el mercado laboral es baja en dichos países y las que participan trabajan en empleo a tiempo completo y reciben beneficios y el acceso al servicio social a través de su estado trabajador. Portugal podría estar representado en el esquema como un punto intermedio entre el modelo Mediterráneo y los regímenes de bienestar liberales debido a su alta tasa de actividad entre las mujeres.

Figura 1. La tipología del Régimen del Bienestar

\begin{tabular}{|c|c|c|}
\hline & $\begin{array}{c}\text { Estado trata } \\
\text { las mujeres como } \\
\text { madres/ esposas }\end{array}$ & $\begin{array}{l}\text { Estado trata } \\
\text { las mujeres como trabajadores }\end{array}$ \\
\hline $\begin{array}{l}\text { Estado protegiendo } \\
\text { frente al mercado }\end{array}$ & $\begin{array}{l}1 \\
\text { MODELO DEL BIENESTAR } \\
\text { DEL HOMBRE-SOSTEN }\end{array}$ & $\begin{array}{c}2 \\
\text { MODELO DEL BIENESTAR } \\
\text { UNIVERSALISTA }\end{array}$ \\
\hline $\begin{array}{l}\text { Estado no } \\
\text { protegiendo frente al } \\
\text { mercado }\end{array}$ & $\begin{array}{c}3 \\
\text { MODELO DEL BIENESTAR } \\
\text { MEDITERRANEO }\end{array}$ & $\begin{array}{c}4 \\
\text { MODELO DEL BIENESTAR } \\
\text { LIBERAL }\end{array}$ \\
\hline
\end{tabular}

Fuente: Trifiletti, 1999

Podemos observar que, al contrario de lo que comentan algunos autores, el modelo del hombre-sostén y mediterráneo no coinciden según esta clasificación. Por ejemplo, en Italia, como las mujeres que no trabajan no reciben unos beneficios particulares, tener un ingreso adecuado para toda la familia es muy difícil sin tener esposas trabajadores, generalmente en actividades por cuenta propia y con ninguna protección. En resumen, "mantener las mujeres pobres en las casas era un lujo que Italia nunca ha disfrutado". " La situación no es tan diferente en otros países mediterráneos, existiendo además otras semejanzas familiares tales como una caída importante en la tasa de natalidad combinada con un largo periodo de dependencia financiera de los hijos adultos respecto a la familia, la creciente importancia de las

\footnotetext{
${ }^{8}$ Ibid, p:51.

Papeles de Europa 
Culfaz, Eylul. El regimen del bienestar del Sur de Europa y los efectos de la crisis 2007 en el bienestar de España.

empresas familiares y la extensión de la propiedad de las viviendas por parte de las familias como un tipo de seguro contra los riesgos sociales.

\section{EL CASO ESPAÑOL COMO REPRESENTANTE DEL RÉGIMEN DE BIENESTAR DEL SUR DE EUROPA}

España ha construido un sistema de protección social de tamaño medio en comparación con otros países de la Unión Europea. En la actualidad, el estado de bienestar español representa una estructura fundamental tanto para la reproducción social como para la legitimación política. Desde su integración en la Comunidad Europea, en 1986, pero principalmente a partir de la Constitución de 1978, España ha seguido un modelo de bienestar marcado por tres rasgos principales: 1) una confluencia en el gasto social con la media de sus socios europeos, 2) la universalización de los derechos sociales (tal como educación, salud, pensiones, etc.) y, por último, 3) un profundo proceso de descentralización política y administrativa.

Aunque España no ha sido ajena a las tendencias a la privatización del bienestar, sin embargo, es posible observar en la historia reciente del bienestar social español una tendencia a alejarse del residualismo y un crecimiento paralelo en el papel del Estado en la esfera del bienestar (Kuhnle, 1997). De hecho, algunas reformas de universalización de la educación, la salud y las pensiones se han practicado por primera vez en España a partir de la llamada transición a la democracia.

\subsection{Confluencia en los gastos sociales con la media Europea}

A lo largo de las décadas de 1970 y 1980, el crecimiento del gasto público en España fue similar al de los países de la OCDE durante los años 1960 y 1970. Además, en ninguno de los países de la OCDE ha aumentado el gasto público tanto como en España desde el año 1975. Según los datos de la OCDE, el gasto público creció de $26 \%$ del PIB en 1975 a más del $47 \%$ en 1995 . Ya en la segunda mitad de la década de 1980, en España, el gasto público per cápita, medido en paridad de poder adquisitivo, fue similar a las equivalentes cifras medias en Alemania, Italia, Francia y el Reino Unido (Moreno, 2004).

Hay que mencionar que en el periodo entre 1980-1992, según datos de Eurostat del año 1993, todos los países del Sur de Europa aumentaron su gasto social a una tasa superior a la media de UE-12 (de 2,7\%) del PIB. Grecia con el 7,1\%, Italia con 6,2\%, Portugal con 2,9\% y España con 4,4\% (Moreno, 1998). En este último país, las partidas correspondientes a la enfermedad, la vejez y el desempleo forman las tres cuartas partes de todos los aumentos en el gasto social. Los gastos de maternidad y de la familia disminuyeron notablemente y se explica porque disminuyeron considerablemente las tasas de natalidad y el tamaño de las familias españolas. Esa situación parece a un reforzamiento de la interpretación de los hogares como pilares fundamentales para el desarrollo del bienestar español (Moreno, 1998).

En resumidas cuentas, España ha experimentado durante el periodo que va de 1975 a 1995 un aumento constante en el gasto público a unos niveles superiores a los de la mayoría de los países europeos. Ha sido el resultado de proveer los medios para cubrir nuevos y costosos programas sociales (universalización de la educación, la 
Culfaz, Eylul. El regimen del bienestar del Sur de Europa y los efectos de la crisis 2007 en el bienestar de España.

salud pública y las pensiones), pero, por encima todo, tenía el objetivo de modernizar y acercar a España con el resto de los países de la UE.

Al igual que en la mayor parte de la Europa continental, el bienestar social en España ha sido tradicionalmente diseñado para el mantenimiento de los ingresos de aquellos ciudadanos que han hecho contribuciones al sistema de la seguridad social durante su vida laboral. La financiación del gasto en protección social se ha obtenido, en gran parte, de las contribuciones de empleadores y los empleados. Sin embargo, en la década de los 90 se produce un cambio significativo, con una transferencia gradual de los fondos públicos del presupuesto nacional a las cuentas de seguridad social. Esto es particularmente relevante en lo que respecta a las pensiones (no contributivas) y a la atención de la salud.

\subsection{Universalización de los derechos sociales}

\subsubsection{Servicio de Salud}

En cuanto a la atención de salud, la Ley General de Sanidad de 1986 establece la creación de un Servicio Nacional de Salud que garantiza el derecho a la asistencia de salud de todos los españoles y de todos los ciudadanos extranjeros residentes en España. ${ }^{9}$ Aunque la cobertura del sistema de salud era muy elevada ya en la década de 1980, con la aplicación de esta legislación fue casi total a el principio de los 90's (Sarasa, 1997). Tres cuartas partes de la financiación de la sanidad española era pública y el resto, en su mayoría, eran pagos directos por parte de las personas (en su mayoría para la atención privada y los medicamentos). Esta era la situación hasta principios de los años 90 . Lo más significativo de este período fue el cambio en la financiación del gasto público desde las contribuciones a los impuestos. En 1980, hasta un $82 \%$ de todo el gasto en salud se sufragaba mediante contribuciones sociales, mientras que en 1993 la cifra fue de 20\% (Gallo de Puelles, 1994 y Rodríguez-Cabrero, 1994). Este cambio hacia un sistema de financiación general por impuestos persigue la universalización de la sanidad pública e incorporar el principio de equidad en la asistencia de salud. Sin embargo, la expansión de la cobertura pública no se ha correspondido con equivalentes aumentos en recursos; por tener un aumento del gasto público en salud en el período 1980-1993 sólo en $0,4 \%$.

\subsubsection{Pensiones}

Desde el comienzo de la década de 1980, se produjo un refuerzo en el crecimiento de los gastos sociales. Sin embargo, y como consecuencia de la movilización liderada por los sindicatos españoles que culminaría en la huelga general del 14 de diciembre de 1988, el gran aumento en las pensiones y en las prestaciones por desempleo se produciría a finales de esa década. En 1990, con la implementación de la Ley de Pensiones no Contributivas, la cobertura tanto para los mayores de 65 años como para las pensiones por invalidez se convirtió en universal (Moreno, 2001). En el período 1980-92, el número de pensionistas aumentó en 2,6 millones $(2,1$, contributivo y 0,5 de carácter no contributivo) y el gasto total aumentó de un

\footnotetext{
${ }^{9}$ Circunstancia que se ha alterado recientemente con el Decreto Ley 16/2012 que deja fuera de determinados serviciosde la asistencia de salud a la población inmigrante no regularizada.
}

Papeles de Europa 
Culfaz, Eylul. El regimen del bienestar del Sur de Europa y los efectos de la crisis 2007 en el bienestar de España.

$5,9 \%$ del PIB (5,8\% contributivo y un $0,1 \%$ no contributivo) al $8,6 \%$ del PIB $(8,1 \%$ contributivo y $0.5 \%$ no contributivo). En promedio, la cuantía de las pensiones de seguridad social aumentó de un 66,5\% del salario mínimo en 1980 al 93,3\% en 1992. A su vez, las pensiones no contributivas (asistencia social) eran $53,3 \%$ del salario mínimo en 1992 (Cruz Roche, 1994).

España ha pasado por importantes cambios demográficos en los últimos tiempos. La población es casi 40 millones con una tasa de crecimiento anual 0,2\% desde el comienzo de la década de 1980. La razón principal de este aumento lento de la población es la disminución de las tasas de fertilidad. En 1980 era 2,1\%, un porcentaje menor que el necesario para asegurar el reemplazo de generación. Al mismo tiempo, la proporción de la población mayor de 65 años pasó de 10,9\% del total en 1980 al $13,2 \%$ en 1990.

Si miramos a la pensión media como porcentaje del PIB per cápita; podemos ver la intensidad de la protección de vejez. Italia y Grecia están arriba del promedio europeo en la pensión de vejez per cápita (62\%), respectivamente con $77,6 \%$ y $78,8 \%$ según los datos de 1993. Esto no es el caso en España con 47,3\%; y con más equilibrio en la distribución de recursos entre las generaciones. Sin embargo, la preocupación general por el aumento drástico de las pensiones en relación con el crecimiento del PIB ha sido lo que ha estado detrás de la modificación de los criterios de la revalorización anual de las prestaciones y un endurecimiento de los requisitos para las pensiones contributivas. Unos criterios más restrictivos en la definición de discapacidad con un control administrativo general, reduce considerablemente el aumento agudo de este tipo de pensiones hasta el año 1985. El proceso en España ha sido algo diferente que en Italia, donde el clientelismo y la connivencia entre los empleadores y los solicitantes potenciales son las causas del mayor gasto público en la Unión Europea para las categorías de discapacidad y "vejez y sobrevivientes" (Ferrera, 1995).

\subsubsection{Educación}

La universalización del sistema educativo ha dado lugar a una cobertura educativa del $100 \%$ sobre la población del grupo de edad de 4-16 años. Según los datos de Encuesta de Población Activa (EPA) en 1992, la cobertura educativa de las mujeres es mayor para los grupos de edad de 16-29 años. Hay que mencionar que el $63 \%$ de las mujeres estaban recibiendo educación formal, en comparación con el $53 \%$ de los hombres. Además, hubo una diferencia importante, sobre los géneros para la gente de 20-24 años entre 1980 y 1992. El impacto de las reformas educativas sobre el bienestar del país es significativo. Incluso años después de los primeros cambios introducidos en el sistema educativo público, sus efectos redistributivos son evidentes.

\subsection{Proceso de descentralización}

Autores como Moreno señalan que, después de todo, el factor más relevante para el desarrollo del bienestar en España ha sido el profundo proceso de descentralización -tanto en la planificación como en la ejecución de las políticas- que han tenido lugar desde 1997 (Moreno, 1997). El resultado en el marco institucional de la interacción entre los gobiernos central, regional y local, responde a la naturaleza de un proceso 
Culfaz, Eylul. El regimen del bienestar del Sur de Europa y los efectos de la crisis 2007 en el bienestar de España.

de reacomodación del poder entre los diferentes niveles espaciales. Ello conlleva cierta incertidumbre institucional que acompañada de una federalización gradual de la política en España (Moreno, 1997). El país ha pasado por una transformación sustancial en lo social, económico y político desde la Constitución de 1978. En términos presupuestarios, las variaciones fueron sustanciales en el período 19781995: el gasto del gobierno central pasó del $90 \%$ al $62 \%$; el del gobierno regional pasó del 0\% al 24\%, y el gobierno local, del 10\% al 14\% (Moreno, 2004).

Según la Constitución de 1978, la asistencia social es competencia exclusiva de los Comunidades Autónomas. Estas usaron estas herramientas principalmente para fines de legitimización institucional. Las iniciativas tomadas por algunas comunidades autónomas han sido imitadas por otras, terminando por configurar esta dinámica el sistema de protección público. De gran relevancia para este trabajo han sido los programas de ingresos mínimos. El ingreso mínimo familiar fue introducido en el País Vasco, en 1998, para combatir la pobreza y las situaciones de exclusión social en la región. Esto constituyó un precedente para los futuros programas de ingresos mínimos en otras comunidades. Aunque hay un grado de diversidad en el diseño de políticas y en la cobertura de las mismas, los programas de ingreso mínimo tienen el objetivo de combinar los beneficios monetarios con las políticas de inserción social, principalmente a través de la promoción del empleo y los planes de formación profesional. Hay que resaltar que estos programas han tenido un impacto muy significativo en el debate sobre la formación de una red de seguridad en España.

La relación entre el gobierno regional y local es significativa para el desarrollo del bienestar en España. En efecto, la interacción entre los instituciones centrales y periféricas es una variable estructurante que pre-determina los resultados de bienestar en la España contemporánea. El Plan de Prestaciones Básicas de Servicios Sociales concertado en 1988 por los tres niveles de gobierno ha sido importante para la ampliación de los servicios sociales a la población en general (particularmente en las áreas de información y asesoramiento, prevención e inserción social, servicios de atención diaria a las personas con discapacidad y edad avanzada, vivienda para mujeres maltratadas, madres solteras, huérfanos o los menores que viven en contextos de violencia y las personas sin hogar).

\subsection{Otras consideraciones de interés para terminar de caracterizar al sistema de bienestar español}

Según la Encuesta de Población Activa (EPA) (Ministerio de Empleo y Seguridad Social, 38$)^{10}$ la tasa de desempleo en España es de las más altas de la Unión Europea. Dada la alta tasa de desempleo en España, algunos autores se sorprenden de que la situación social sea relativamente estable en el país, especialmente en relación con los jóvenes. Varios autores señalan que la explicación de la situación puede estar relacionada con dos aspectos del país. Por un lado, con un gasto público significativo en materia de prestaciones por desempleo, con la proporción más alta de todos los países de la UE-12 (Comisión Europea, 1995). Sin embargo no puede ser una explicación significativa, al menos en el caso de los jóvenes. Porque para acceder a la prestación por desempleo hay

\footnotetext{
${ }^{10}$ http://www.empleo.gob.es/es/estrategia-empleo-joven/archivos/Analisis_de_Contexto.pdf

Papeles de Europa

Vol. 27, Núm. 1 (2014): 105-136

http://dx.doi.org/10.5209/rev_PADE.2014.v27.n1.47014
} 
Culfaz, Eylul. El regimen del bienestar del Sur de Europa y los efectos de la crisis 2007 en el bienestar de España.

que haber trabajado anteriormente y la mayoría de los jóvenes españoles son desempleados que aún no han accedido a su primer empleo. Por otro lado, lo relacionan con la existencia de redes de micro-solidaridad, por el apoyo a través de las redes familiares.

Otro hecho relevante para el modelo de bienestar español es la evolución de la participación de la mujer en el ámbito del trabajo mercantil. El hecho más importante en la composición de la fuerza de trabajo español es la participación, cada vez mayor, de las mujeres. Un cambio en las prioridades en la mayoría de las mujeres con respecto a su posición tradicionalmente subordinada dentro del mercado laboral y su compromiso con la educación de los hijos. Este cambio en el papel de las mujeres en el mercado laboral y dentro de las familias tiene repercusiones importantes para el Estado de Bienestar español. La generación nacida entre 1950 y 1970 se caracteriza por mujeres bien educadas y comprometidas con las actividades profesionales. Este modelo provoca un aplazamiento para dar a luz a su primer hijo. Además, las tasas de matrimonio han disminuido como resultado del desempleo, los problemas para conciliar las expectativas de empleos adecuados a sus mayores niveles de cualificación y los crecientes costes de vida, especialmente en las zonas urbanas. Las transformaciones en los modelos familiares son similares en otros países del sur de Europa, que se reflejan en las actitudes ambivalentes frente a la familia por parte de las mujeres (Flaquer, 1995).

Al tener la provisión pública un carácter fragmentado, mezclando un modelo relacionado con los ingresos (income related) y un modelo universalista, la evaluación de la prestación de asistencia social no es fácil. En relación con el «efecto Mateo» las valoraciones difieren según los autores: algunos señalan que quién más se beneficia de este modelo de bienestar es la parte de la población nopobre, convirtiéndose este rasgo en la característica más desigual del estado de bienestar. Por otro lado, otros autores, señalan que permitir que se beneficien también los que no son destinatarios principales de las actuaciones sociales fomenta las coaliciones posibles entre las clases menos favorecidas y los sectores de la clase media para la continuación de las políticas de bienestar del Estado. En resumen, el problema es que los servicios y beneficios sociales no siempre llegan a los más necesitados en el caso del Bienestar del Sur, incluyendo a España.

\section{EL BIENESTAR EN ESPAÑA EN ÚLTIMOS AÑOS Y EL EFECTO DE LA CRISIS}

En este apartado, voy a intentar explicar los efectos de la última crisis de 2007 sobre el bienestar español con la ayuda de los datos de 2000s. Como se ha señalado en la introducción, el término bienestar es un concepto amplio y multidimensional y, por ello, es un variable difícil de medir. He elegido algunos indicadores para explicar la tendencia general de la protección social en España en dicho periodo, siendo consciente del hecho que no es posible aclarar todo mirando únicamente las variables elegidas.

Al analizar los efectos de la crisis sobre el bienestar en España, voy a seguir la evolución cuantitativa que de esta cuestión ha hecho el Colectivo IOE en su 
Culfaz, Eylul. El regimen del bienestar del Sur de Europa y los efectos de la crisis 2007 en el bienestar de España.

"Barómetro Social de España".11 Primero, empezaremos con los datos sobre las condiciones del bienestar, intentando reflejar los cambios en la calidad de vida de las personas, hogares y familias. En el segundo lugar, continuaremos con la evolución de la protección social mirando el gasto público en materia social, para ver los efectos de la crisis sobre el proceso de la universalización de los derechos sociales y las condiciones de desempleo, tal y como he mencionado en el apartado previo.

\subsection{Las Condiciones del bienestar y la evolución de la protección social durante el periodo de crisis en España}

Para ver la evolución de las condiciones del bienestar y los efectos de la crisis, lo mejor es empezar a analizar la evolución de la renta y patrimonio de los hogares en la última década. El patrimonio total de los hogares por persona (financiero e inmobiliario) creció a un ritmo significativo en los primeros años del siglo XXI; sin embargo, con la crisis, a partir del año 2007 se redujo intensamente. Cuando miramos a la tasa de crecimiento, podemos ver claramente el efecto de la crisis sobre el patrimonio de hogares: «...desde 2007, la crisis dio paso a un descenso anual del 4,1\% con el mayor pico negativo en $2008(-10,8 \%){ }^{12}{ }^{12}$ La renta per cápita de los hogares se incrementa hasta 2009, pero muestra un descenso en el último año para el que hay datos disponibles, el 2010, "coincidiendo con la nueva política de recortes del gobierno del PSOE». ${ }^{13}$

Grafico 1. Renta y Patrimonio de Hogares por persona en el periodo 2000-2010 (el eje derecha es para las tasas de crecimiento)

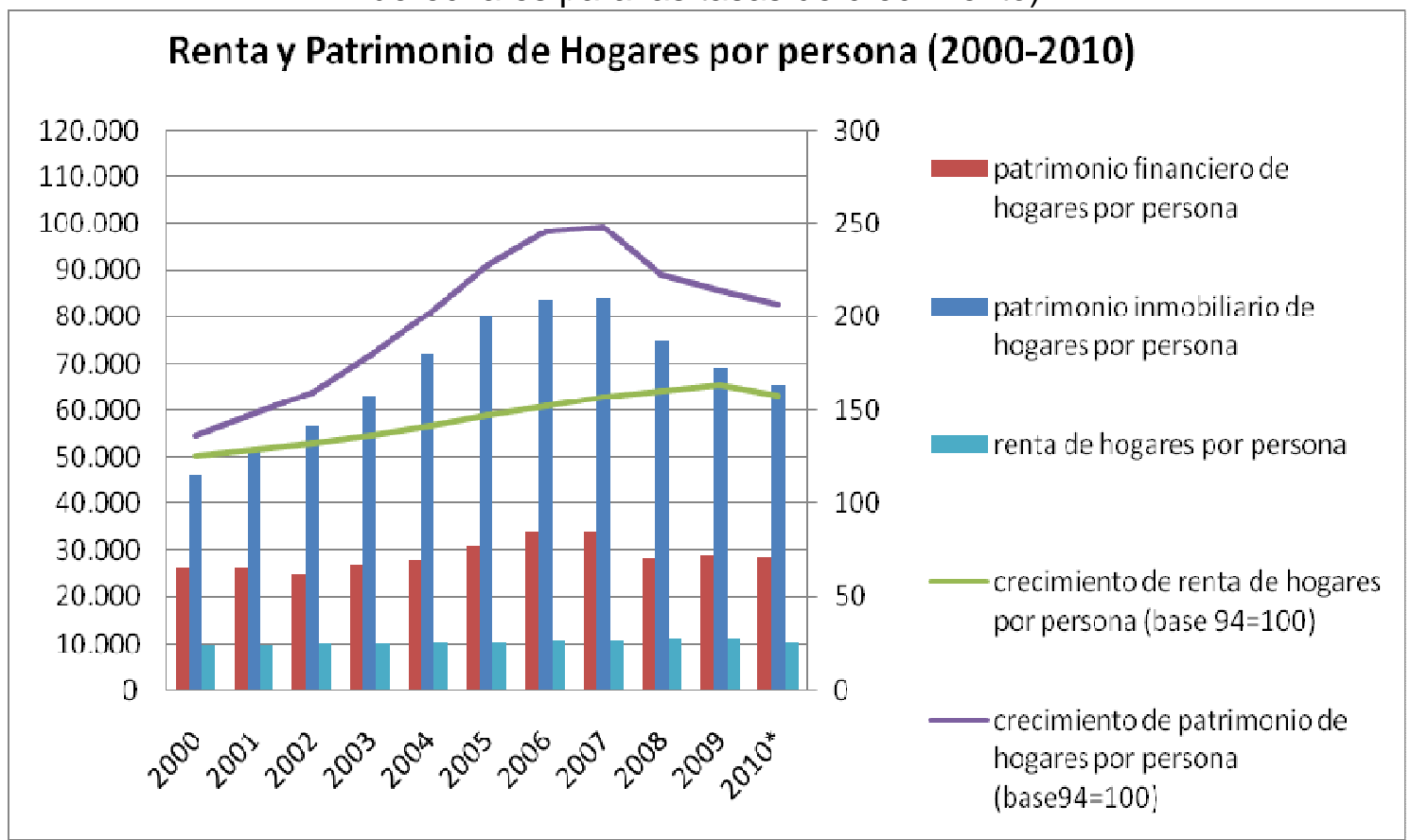

Fuente: www.barometrosocial.es

\footnotetext{
${ }^{11}$ Como se señala en la página web del «Barómetro Social de España», éste es un proyecto de evaluación continua de la situación social de España realizado por Colectivo Ioé, equipo especializado en la investigación social, y patrocinado por FUHEM-Ecosocial. El Barómetro Social propone un sistema de 189 indicadores sociales -todos procedentes de fuentes oficiales-e índices sintéticos elaborados por los autores correspondientes a once ámbitos sociales que ofrecen una visión de conjunto del bienestar. http://barometrosocial.es/

${ }^{12}$ Colectivo IOE, "Crece la desigualdad en Espana",p.2.

${ }^{13}$ Ibid, p.2.
}

Papeles de Europa 
Culfaz, Eylul. El regimen del bienestar del Sur de Europa y los efectos de la crisis 2007 en el bienestar de España.

Estos datos no son suficientes para reflejar la situación social en España al ocultar la forma de distribución de la renta y patrimonio. Según los datos en el www.barometrosocial.es, el índice de GINI de España siempre ha tenido un nivel más desigual que la media europea. Aunque en el periodo 2005-2007 se había producido una cierta convergencia con la UE, como consecuencia de la crisis a partir de 2007 la brecha se incrementa mucho más que antes. Además, si se tiene en cuenta la distribución de la riqueza por cuartales en los años 2002, 2005 y 2009 (gráfico 2), se puede comprobar que el incremento de la proporción de la riqueza que se concentra en los hogares más ricos y el descenso de la que está en poder de la clase media y pobre, muestra la creciente brecha de desigualdad que está surgiendo como consecuencia de la crisis entre las diferentes clases sociales. En el año 2009, 67\% de la riqueza estaba en manos de los hogares más ricos y sólo el $1,3 \%$ correspondía al $25 \%$ de los hogares más pobres.

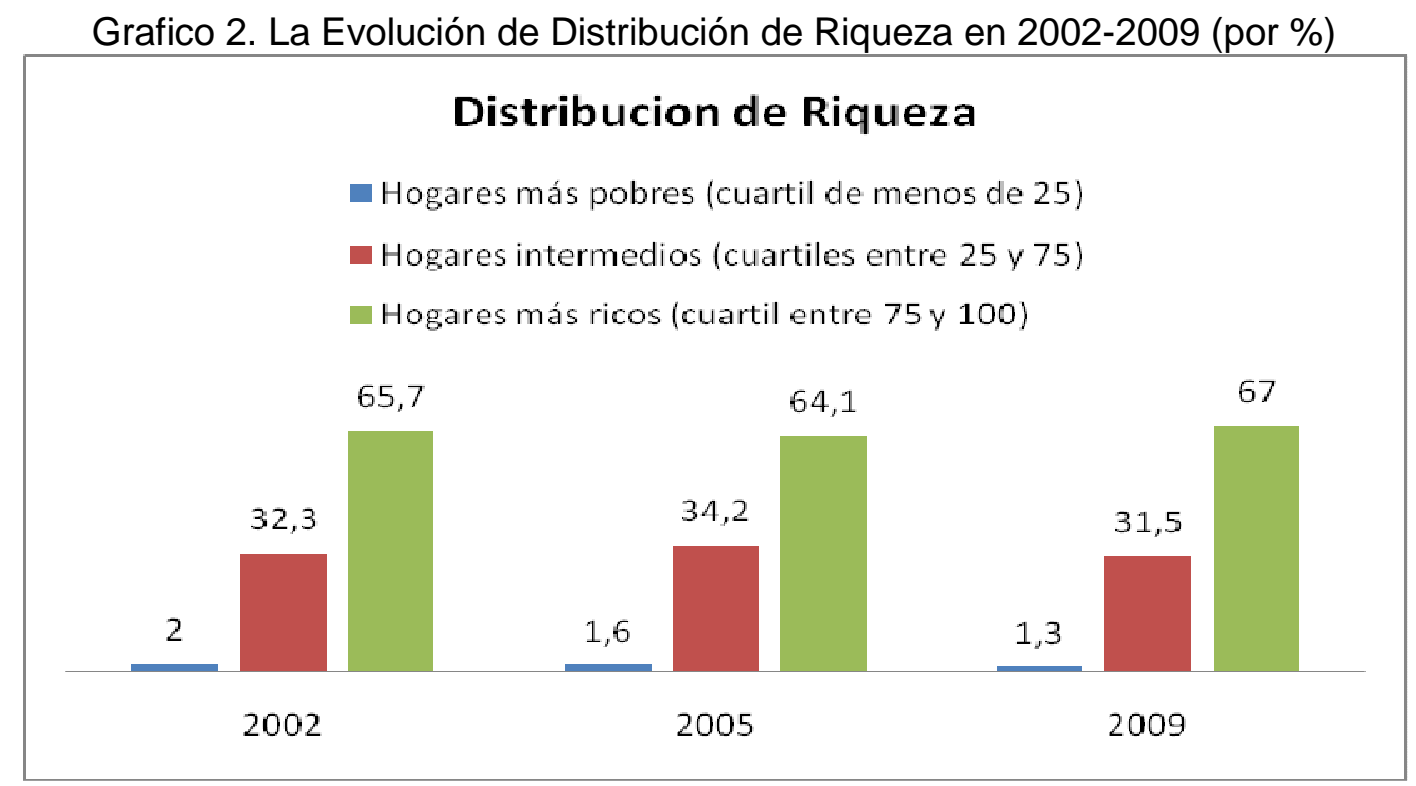

Fuente: www.barometrosocial.es

Por otro lado, el incremento de la participación del patrimonio financiero dentro del total del patrimonio de los hogares junto al descenso en la tasa de crecimiento de renta por persona y la distribucion desigual por cuartiles, permite concluir que los hogares están mucho más endeudados que antes. Segun los datos de Encuesta Financiera de las Familias de Banco de España del año $2008^{14}$, el endeudamiento de los hogares se multiplicó por cuatro en el periodo comprendido entre 1994 y 2007, distribuyéndose de manera muy desigual la carga de la deuda entre los hogares.

\subsubsection{Los efectos de la crisis sobre el gasto público en materia social}

En este apartado se utiliza la metodologia correspondiente al Sistema Europeo de Estadísticas Integradas de Proteccion Social (SEEPROS) impulsada por la Oficina de Estadística de la Unión Europea (Eurostat). Según SEEPROS, los gastos públicos que están relacionados con la protección social incluyen ocho elementos: 1)Salud, 2)Invalidez, 3) Vejez, 4) Supervivencia, 5) Familia-Hijos, 6) Desempleo, 7)

\footnotetext{
${ }^{14} \mathrm{http} / / / \mathrm{www}$. bde.es/f/webbde/SES/estadis/eff/eff2008_be1210.pdf 
Culfaz, Eylul. El regimen del bienestar del Sur de Europa y los efectos de la crisis 2007 en el bienestar de España.

Vivienda y 8) Exlusión Social. Si miramos la participacion de cada esfera en el total del gasto social, y éste último como porcentaje del PIB, podremos obtener una idea aproximada de lo que significa el sistema de protección público en el marco del régimen de bienestar de España.

Grafico 3. Gasto en Proteccion Social ( \%PIB)

(el eje derecha para el porcentaje del gasto total en proteccion social dentro del PIB)

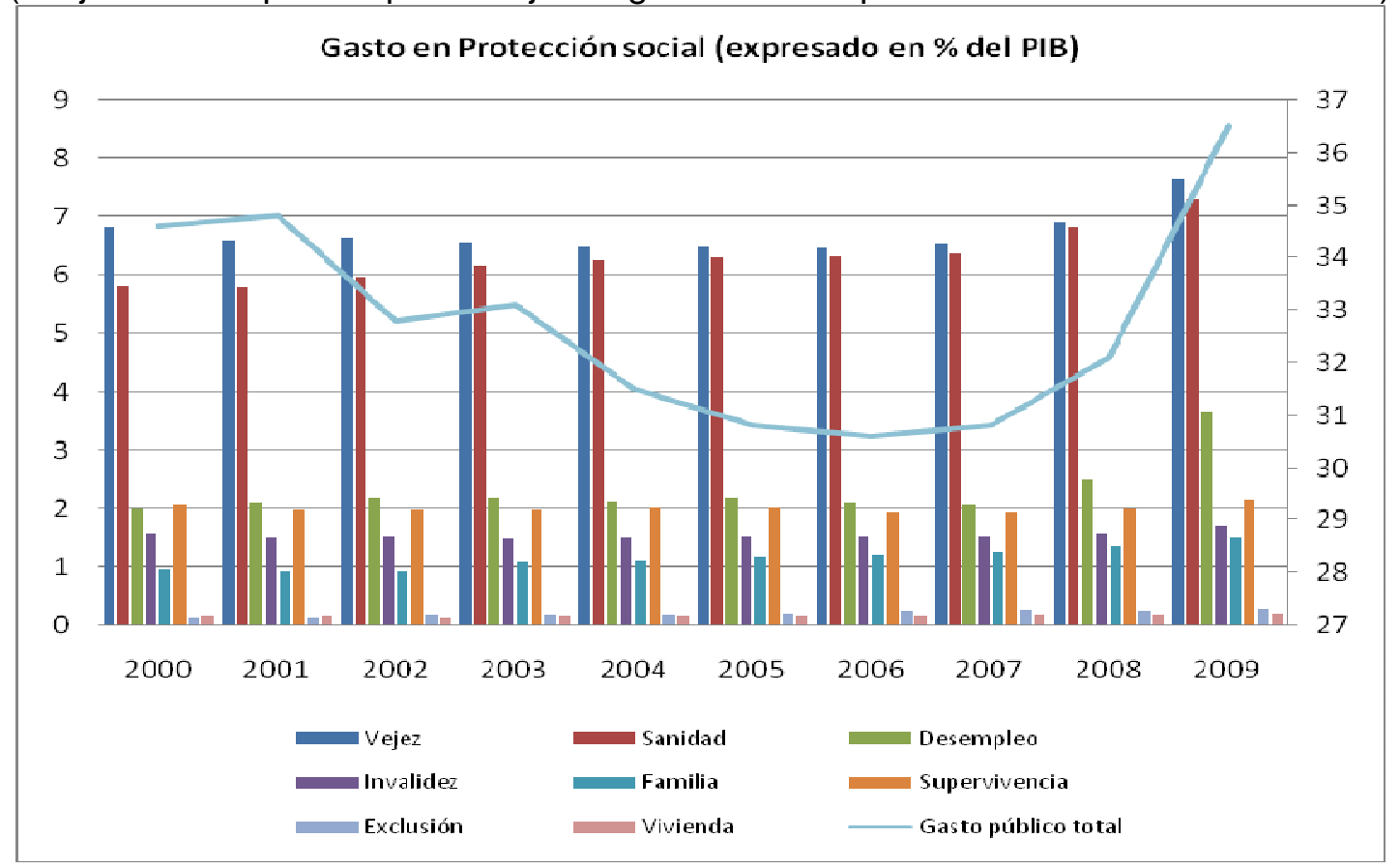

Fuente: www.barometrosocial.es

El porcentaje del gasto público total dentro del PIB tiene una tendencia decreciente desde 2003 hasta el año 2008. A partir de 2008, empieza a aumentar de forma clara, y en el último año, su participación se incrementa desde el 30,8\% al 36,5\%. Si miramos la distribucion del gasto, podemos observar que durante todo el periodo los gastos relacionados con la vejez siempre han sido los más cuantiosos, sobre todo en últimos dos años en los que experimentan un incremento significativo. La segunda partida de gasto es la sanidad y, en tercer lugar, viene el desempleo. La composición del gasto no muestra cambios significativos durante el periodo, salvo en el aumento en el porcentaje de los gastos por desempleo en el ultimo año (2009) debido al extraordinario incremento en el numero de parados en la economía española.

Eurostat no incluye la educación como un elemento de la proteccion social. Por ello, crea un indicador nuevo denominado "gasto en politicas sociales+educación". Según los datos del "Barometrosocial" para el año 2009, la distribucion es la que refleja el gráfico 4. Como son datos de un único año, no es posible ver los efectos de la crisis sobre la composición del gasto social, pero mirando conjuntamente los graficos 3 y 4 , podemos sacar algunas conclusiones. Las pensiones representan el $26 \%$ del gasto social publico para cubrir la poblacion de mayor edad (65 años y más), a traves de prestaciones contributivas y no contributivas (se verá su evolucion en relacion del PIB en el siguiente apartado). La sanidad y la educación son las siguientes partidas más significativas. El porcentaje correspondiente a las 
Culfaz, Eylul. El regimen del bienestar del Sur de Europa y los efectos de la crisis 2007 en el bienestar de España.

prestaciones por desempleo -con un $12 \%$ del gasto social- aumentan con gran fuerza debido a la crisis, convirtiéndose en la cuarta partida más importante .

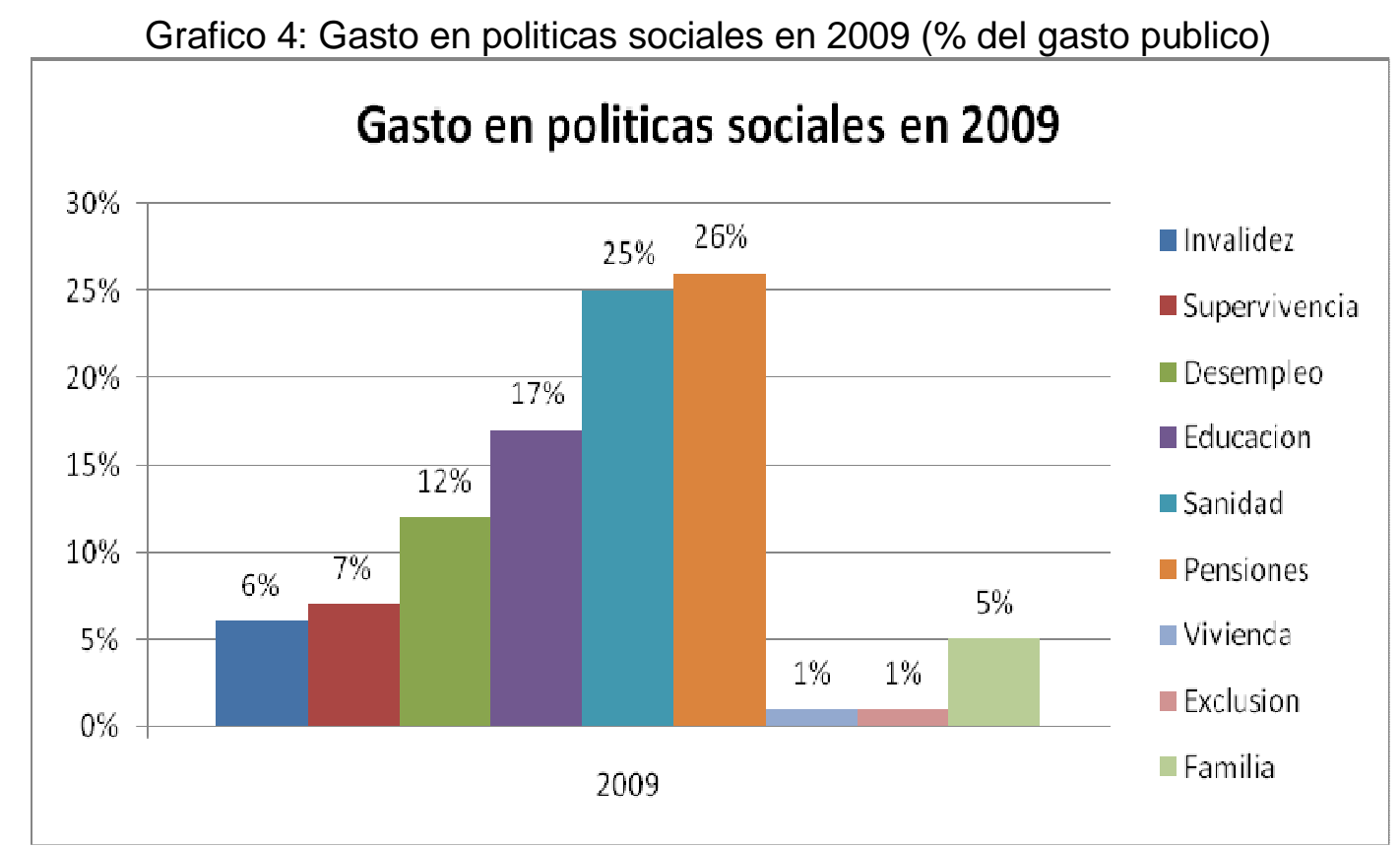

Fuente: www.barometrosocial.es

El gasto social como porcentaje del PIB no muestra un descenso desde que se desata la crisis; al contrario, a partir de 2007 se incrementa significativamente. Particularmente, debido al incremento drástico, entre 2008 y 2009, de la partida destinada a la cobertura del desempleo y a que continúa la tendencia al aumento de la poblacion anciana, con su corrspondiente efecto en las pensiones y los gastos de salud. «Si a ello se unen las medidas de salvamento con dinero público de la banca y las cajas de ahorros en los ultimos años..., el resultado ha sido un elevado déficit fiscal del estado que tuvo su pico mas alto en 2009...dando lugar al problema de la deuda soberana y a la cadena de recortes sociales iniciada en la primavera de 2010 con el gobierno socialista y acelerada después con el Partido Popular...». ${ }^{15}$

\subsubsection{Los efectos de la crisis sobre la universalización de los derechos sociales}

a) Salud

La salud es uno de los ámbitos más importantes del bienestar social. Como ya se ha comentado, la Ley General de Sanidad que entró en vigor en el año 1986 creó un Sistema Nacional de Salud basado en la universalización de las prestaciones de salud a toda la población, en la financiación pública de las mismas y en la descentralización del sistema entre las comunidades autónomas.

Si se tienen en cuenta los datos de mortalidad y esperanza de vida, España muestra una evolución positiva (bajando la tasa de mortalidad e incrementando su esperanza

\footnotetext{
${ }^{15}$ Colectivo IOE, "Crece la desigualdad en Espana" p.7.

Ver Plataforma por la Nacionalizacion de las Cajas de Ahorro, "La Reestructuracion del Sistema Financiero Espanol" en www.nacionalizacioncajamadrid.wordpress.com
} 
Culfaz, Eylul. El regimen del bienestar del Sur de Europa y los efectos de la crisis 2007 en el bienestar de España.

de vida), incluso por encima del promedio europeo ${ }^{16}$. Sin embargo, cuando se atiende a las causas externas de muerte, observamos una tendencia decreciente en los accidentes de varios tipos y un incremento en los suicidios a partir de 2007. Por otro lado, si miramos las enfermedades crónicas más habituales en España, el porcentaje de la población de 16 y más años afectada por depresión muestra un incremento impresionante en los últimos anos. Aunque pueden ser varias las razones de este fenómeno, 'no es descabellado relacionarlo con el efecto de la crisis sobre el bienestar de salud de la población.

Grafico 5: La evolución del gasto de Salud Público y Privado en Relación al PIB en el periodo 1991-2009 (Base 100=1991)

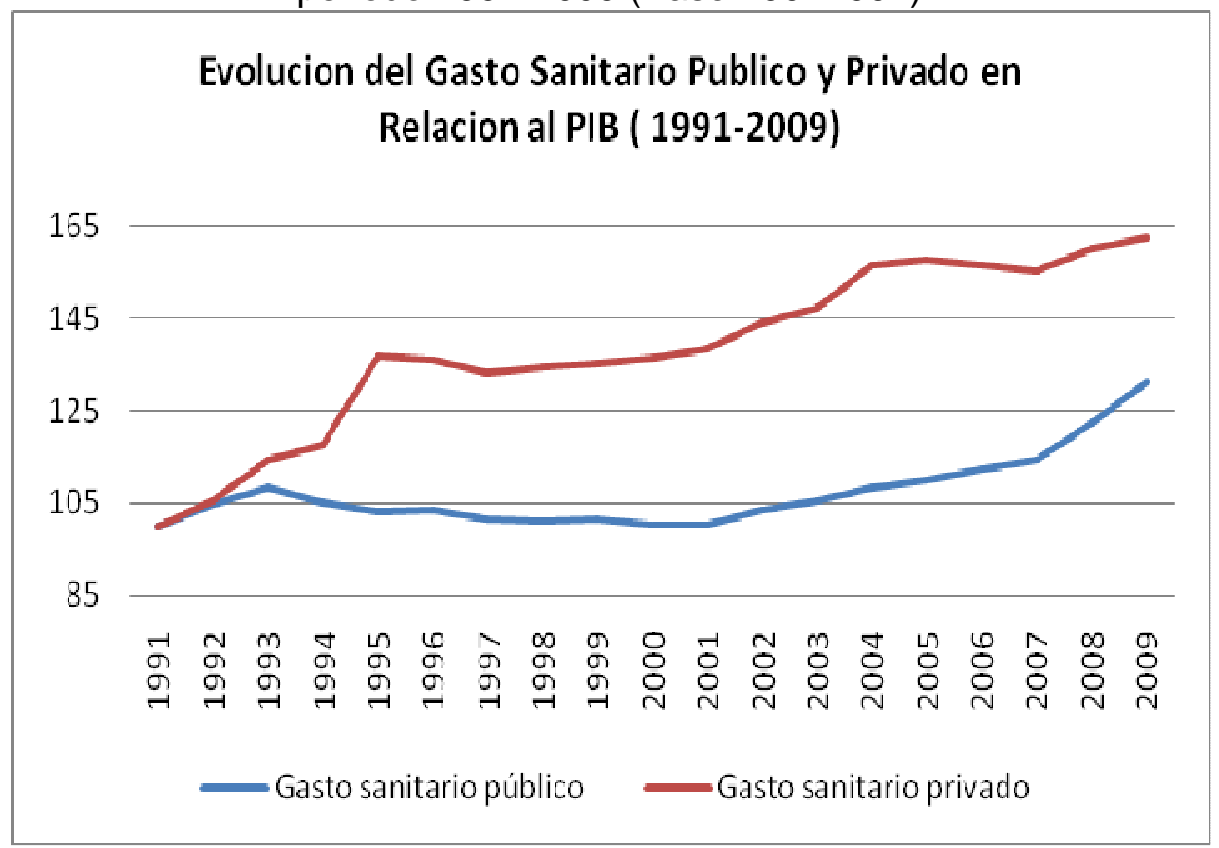

Fuente: www.barometrosocial.es

Mirando al grafico 5, la proporción del gasto público en sanidad dentro del PIB continúa su dinámica creciente en la última década. Si miramos la distribución del gasto de salud total entre público y privado, se puede comprobar el enorme peso que representa el primero. En otro lado, según los datos de OCDE, en el año 2009, el $9,5 \%$ del PIB estaba dedicado al gasto de salud, siendo el 6,99\% de carácter público y el $2,51 \%$ privado. Aunque el sector público parece muy importante en España dentro del conjunto del gasto de salud, cuando lo comparamos con otros países, podemos ver que el promedio que en la OCDE tiene el peso del gasto de salud público dentro del gasto de salud total es del 74,8\%, mientras que en España apenas alcanza el 73,6\%. Los porcentajes de Francia, Alemania, Italia y Reino Unido son respectivamente; $77 \%, 76,8 \%, 79,6 \%$ y $83,2 \%{ }^{17}$

Por otro lado, hasta el año 2004 el crecimiento del sector privado dentro del gasto de salud fue mucho más intenso que el del sector público (Grafico 5). Sin embargo, durante el periodo 2004-2007 se produce un estancamiento del sector privado, por lo que las tasas se empezaron a acercar. Con todo, la convergencia empezó a manifestarse más claramente a partir de la crisis, con el rápido crecimiento del sector

\footnotetext{
${ }^{16} \mathrm{http}: / /$ barometrosocial.es/salud

${ }^{17}$ OCDE, Health Data 2012.
} 
Culfaz, Eylul. El regimen del bienestar del Sur de Europa y los efectos de la crisis 2007 en el bienestar de España.

público en el gasto de salud. En consecuencia, se puede comprobar que la crisis ha afectado más negativamente al sector privado y ha hecho que se incremente el peso (y la correspondiente carga de gasto) del sector público.

\section{b) Pensiones}

«El sistema de pensiones es la fuente principal de ingresos para la práctica totalidad de las personas jubiladas, llega a más de un tercio de los hogares españoles y absorbe el 9,6\% del PIB ( la media de la Unión Europea representa más del $12 \%) » .^{18}$ La relación entre la población de 65 y más años y el número pensiones es crucial para entender la amplitud de la cobertura del sistema. Según los datos del Ministerio del Empleo y Seguridad Social de España, en el año 2010 había una población de 7,7 millones de personas ancianas (edad de 65 y más) y la suma de las pensiones de jubilación y viudedad ascendía a 7,68 millones, lo que significa que la cobertura del sistema español es casi universal.

Grafico 6. La relacion de la Variacion Anual de las Pensiones y El PIB Espanol ( $€$ constantes con base en 2000)

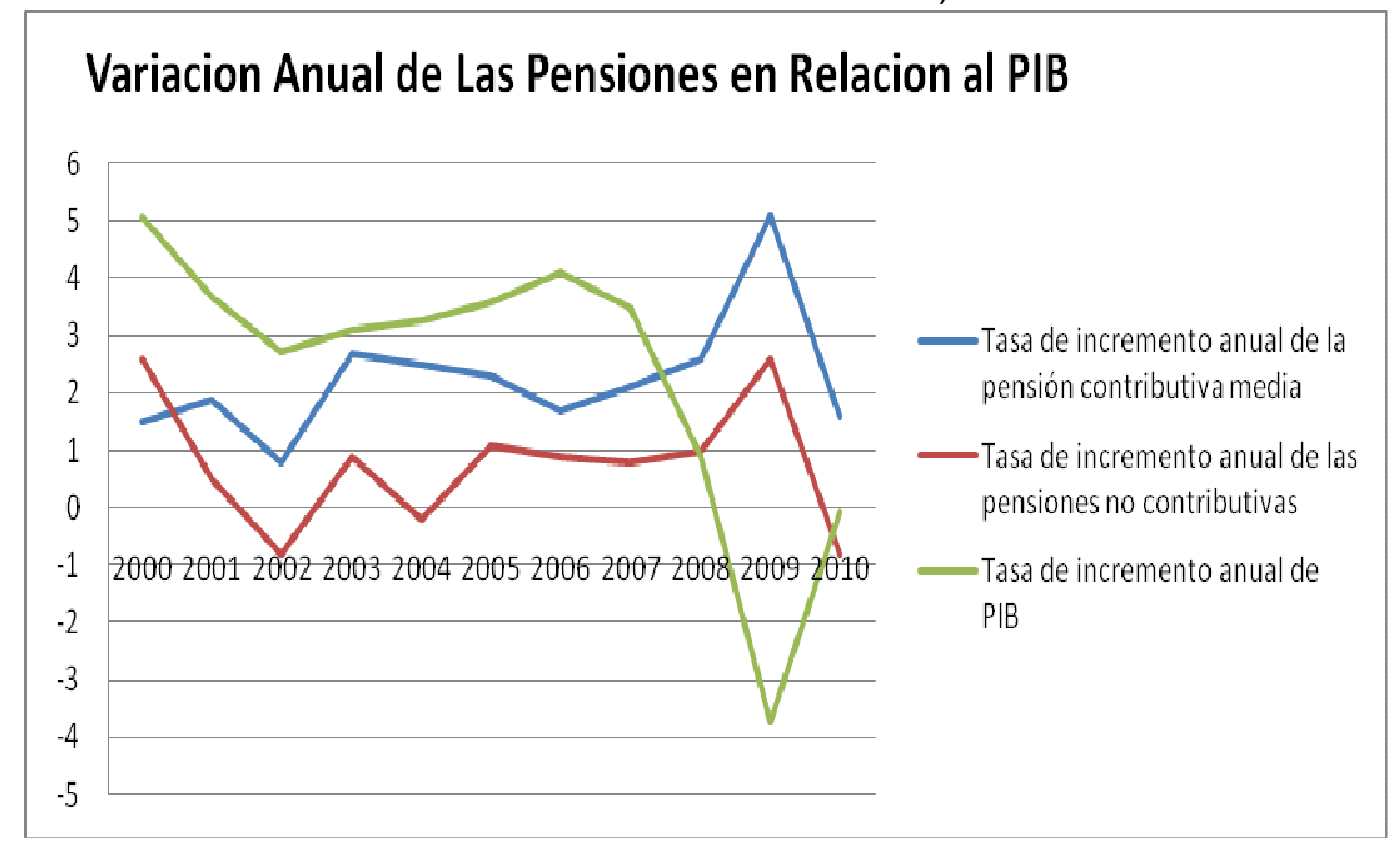

Fuente: www.barometrosocial.es

Antes de mirar los datos con detalle, resulta conveniente diferenciar entre las pensiones contributivas ${ }^{19}$ y las no contributivas. ${ }^{20}$ Del conjunto de las pensiones de

\footnotetext{
${ }^{18}$ Colectivo IOE (2008), Barometro Social de Espana, Analisis del periodo 1994-2006 a partir de un sistema de indicadores; p.219

${ }^{19}$ Según la definición de Ministerio del Empleo y Seguridad Social de España, las pensiones contributivas «son prestaciones económicas y de duración indefinida, aunque no siempre, cuya concesión está generalmente supeditada a una previa relación jurídica con la Seguridad Social (acreditar un período mínimo de cotización en determinados casos,...), siempre que se cumplan los demás requisitos exigidos», e incluyen las pensiones por jubilación, incapacidad permanente y fallecimiento.

http://www.seg-social.es/Internet_1/Pensionistas/Pensiones/ModalidadesClases/index.htm

${ }^{20}$ las pensiones no contributivas «son prestaciones económicas que se reconocen a aquellos ciudadanos que, encontrándose en situación de necesidad protegible, carezcan de recursos suficientes para su subsistencia en los términos legalmente establecidos, aun cuando no hayan cotizado nunca o el tiempo suficiente para alcanzar las
} 
Culfaz, Eylul. El regimen del bienestar del Sur de Europa y los efectos de la crisis 2007 en el bienestar de España.

jubilación y viudedad, 7,4 millones de las prestaciones son contributivas y el resto $(259,626)$ no contributivas (asistenciales de vejez). En consecuencia, dentro del total de las pensiones las contributivas forma la mayoría con un porcentaje del $96 \%$.

En términos reales, las pensiones contributivas y no contributivas apenas muestran cambios importantes después de la crisis 2007. Sin embargo, la relación entre las tasas de crecimiento anual de las pensiones medias -tanto contributiva como no contributiva- en relación con el PIB anual sí refleja de alguna manera el efecto de la última crisis. En el gráfico 6 , se muestra el cambio en esta relación. Hasta finales de 2007, las tasas de crecimiento de ambos tipos de pensiones siguen por debajo de la tasa de crecimiento de PIB, pero por el efecto de la crisis la tasa de incremento del PIB cae drásticamente y queda por debajo del ritmo de las prestaciones. Además, justo durante el período que va desde el año 2008 hasta el 2009, las pensiones contributivas y no contributivas crecen mucho más rápido que antes y forman un pico en el gráfico que dura solo un año, para volver a caer otra vez.

Grafico 7. Porcentaje de los pensionistas por debajo de la Pensión Mínima de Jubilación

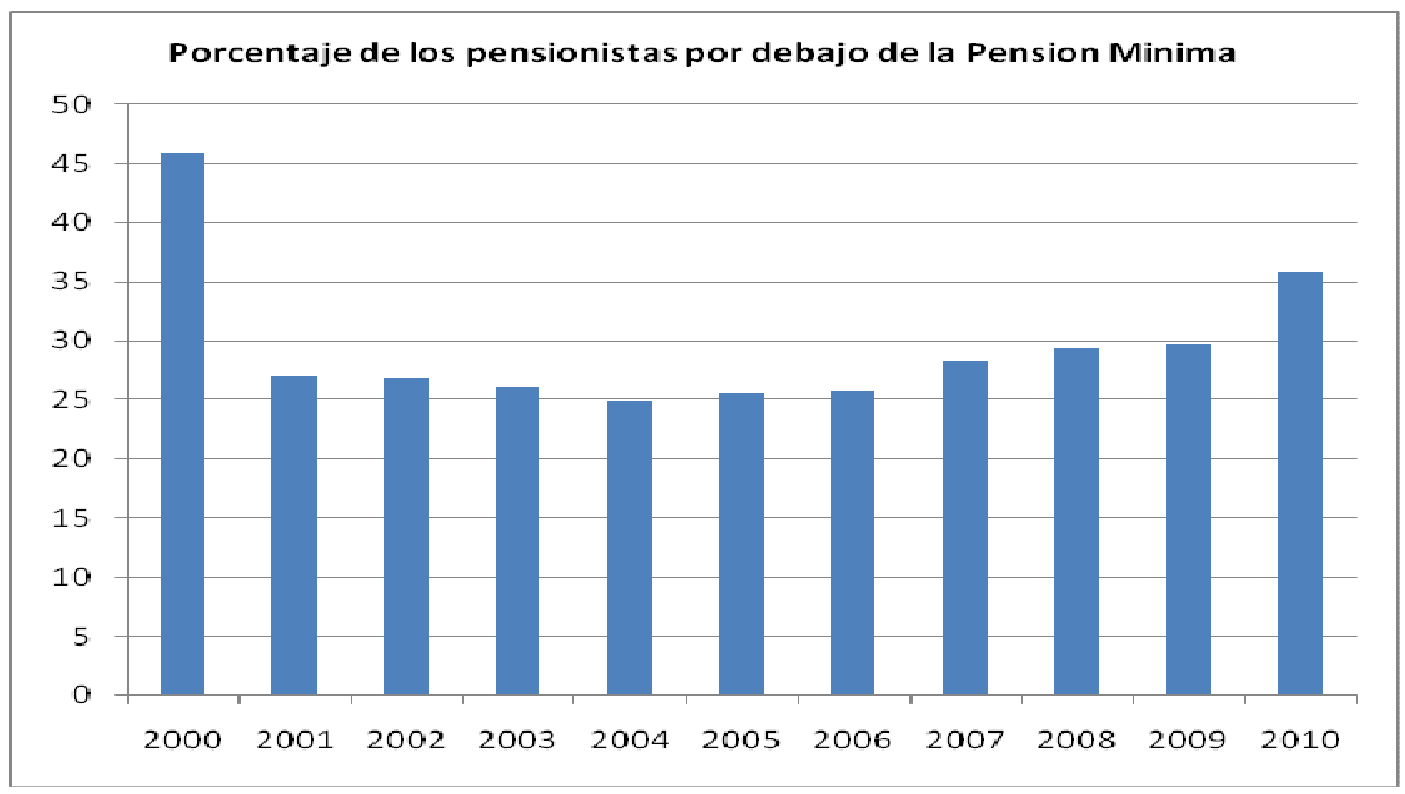

Fuente: www.barometrosocial.es

Tal vez, el análisis del porcentaje de los pensionistas por debajo de la pensión mínima sea el indicador más ilustrativo para ver los efectos de la crisis en este ámbito. El gráfico 7 refleja la cantidad de pensionistas por debajo de la pensión mínima. Para contrarrestar las bajas pensiones, el gobierno español creó un sistema de complementos para garantizar un mínimo de subsistencia de toda la gente. Ello provocó que, entre el año 2000 y 2001, hubiera un cambio drástico en el porcentaje de los pensionistas por debajo de la pensión mínima, una caída del $45,9 \%$ al $27 \%$, situándose el porcentaje en torno a esos valores hasta 2007. Sin embargo, a partir de ese año, el porcentaje se eleva hasta el 35\% que refleja el año 2010. Aunque no hay un cambio significativo en las pensiones contributivas y no contributivas en

prestaciones del nivel contributivo» Dentro de esta modalidad, se encuentran las pensiones de invalidez y jubilación.

http://www.seg-social.es/Internet_1/Pensionistas/Pensiones/ModalidadesClases/index.htm\#35116

Papeles de Europa 
Culfaz, Eylul. El regimen del bienestar del Sur de Europa y los efectos de la crisis 2007 en el bienestar de España.

términos reales, y también sigue una cobertura amplia para la población anciana, el porcentaje de los pensionistas por debajo de la pensión mínima aumenta considerable. Esta circunstancia se puede explicar por la evolución durante últimos anos de las pensiones no contributivas (reflejada en el grafico 6); como la mayoría de los pensionistas que residen pensiones inferiores a la mínima, son de carácter no contributivo, el que la tasa del incremento anual de estas últimas caiga en picado desde el año 2009 provoca que aumente el porcentaje de pensionistas por debajo de la pensión mínima.

Al analizar la evolución de la distribución de las pensiones dese el año 2006 hasta el año 2010 (justo cuando hay un incremento de 6\% en el porcentaje de los pensionistas por debajo de la pensión mínima), se puede comprobar cómo aumenta la desigualdad de manera significativa entre los pensionistas con mayor y menor ingreso. El gráfico 8 clasifica a los perceptores en tres grupos: los que reciben una por debajo de la pensión mínima de jubilación (PMJ), los que reciben una prestación que se encuentra entre la PMJ y el doble y más del doble de la PMJ en el año 2006 y 2010. Además se pueden ver los porcentajes respecto al total de los perceptores.

Entre 2006 y 2010, hay un empeoramiento en la distribución de las pensiones debido al incremento del porcentaje de los perceptores por debajo de PMJ y a la caída del porcentaje entre los perceptores del grupo medio, manteniéndose el porcentaje de los perceptores que reciben más del doble de PMJ de forma estable. Por otro lado, cuando miramos el importe de las pensiones mensuales, se puede percibir una evolución incierta en cuanto a la desigualdad. Si bien es cierto que la relación entre el importe máximo y mínimo disminuye en el periodo que transcurre entre 2006 y 2010, el porcentaje de los perceptores medios disminuye considerablemente, aumentando con ello la concentración de los pensionistas que se sitúan en los extremos (incrementándose con ello la dispersión).

Grafico 8. Número de perceptores, Pensión mínima de jubilación por mes y Porcentaje respecto al total de perceptores en 2006 y 2010 en España

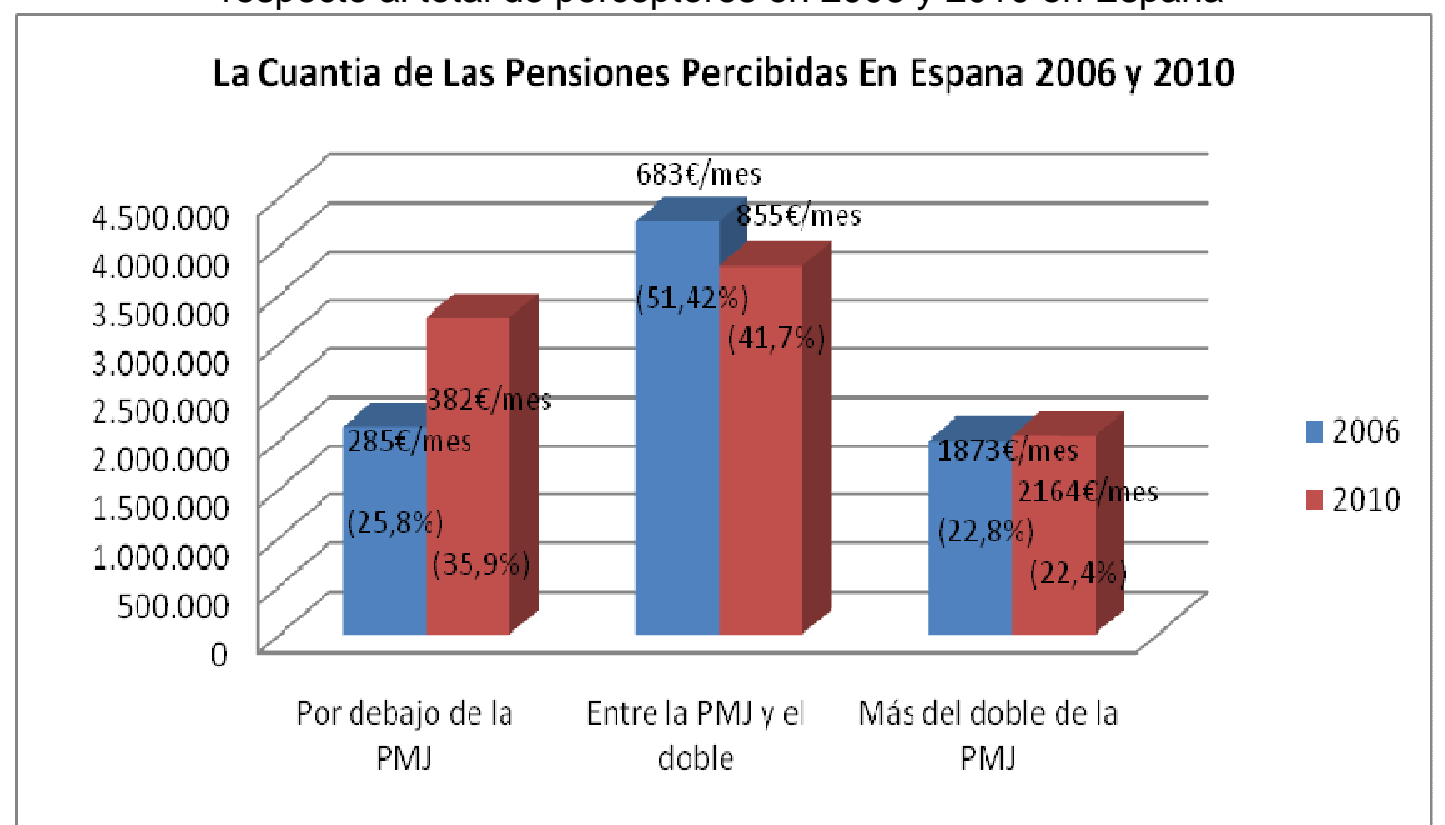

Fuente: www.barometrosocial.es 
Culfaz, Eylul. El regimen del bienestar del Sur de Europa y los efectos de la crisis 2007 en el bienestar de España.

\section{c) Educación}

Aunque según los criterios al uso, no se incluya la educación como un componente del gasto social, sin embargo, se podría considerar perfectamente como un componente fundamental por su contribución a la igualdad de oportunidades y a su función niveladora o de equidad. A parte de esta cuestión (el de su contabilización como gasto social), es un elemento importante para evaluar el bienestar social.

El nivel educativo de la población adulta española ha mejorado claramente en las últimas décadas, al lograr unas tasas crecientes en el porcentaje de personas adultas con estudios postsecundarios y una tendencia decreciente en el porcentaje de las personas adultas sin estudios primarios. Podemos relacionar esta circunstancia con el proceso iniciado con la Ley General de Educación en 1970 y posteriormente, con Ley Orgánica General del Sistema Educativa (LOGSE) en 1990, donde se planteó la plena escolarización hasta los 16 años. ${ }^{21}$

Sin embargo, los puntos débiles del sistema educativo español se encuentran en la elevada tasa de abandono temprano y en el elevado fracaso escolar. A partir de los datos de los resultados escolares usando varios indicadores, se concluye que aproximadamente la mitad del alumnado repite algún curso y que la tendencia es creciente: según los datos del "Barometrosocial"22; la proporción del porcentaje de alumnado que ha repetido algún curso al cumplir los 15 años, era 41,6\% en 1994 y aumentó al 42,3\% en 2008 con una tasa de crecimiento de 0,7\%. También, la tasa de graduados en bachillerato decrece a partir de 2007 y el porcentaje de jóvenes que han abandonado la escuela sin terminar la educación secundaria aumenta. El año 2008 muestra los peores resultados educativos de la última década. Cuando estos resultados se comparan con los de los países de UE-27, encontramos que España es el tercer país con mayor tasa del abandono educativo temprano entre los jóvenes.

El indicador principal para observar la financiación de la educación es el gasto público en educación en relación al PIB. Sin embargo, «...dicho indicador no expresa la magnitud de la inversión de la sociedad en educación, puesto que una parte de la financiación es de origen privado; por otra parte, la relación gasto/PIB no depende solo de los recursos destinados a educación sino de las variaciones del alumnado que puede evolucionar, tal y como ha ocurrido en España, a un ritmo inverso al PIB... Con el fin de abordar estas circunstancias recurrimos a un segundo indicador: el gasto total medio (público y privado) por alumno en relación al PIB por habitante $(\mathrm{en} \%){ }^{23}$

Como se comprueba en el gráfico 9 (que toma el año 1994 como base), el gasto publico en educación en relación al PIB no ha dejado de crecer, pero no así el gasto total en educación por alumno en relación al PIB per capita. A partir del momento en que se desata la crisis, aumenta este último indicador, pero debido

\footnotetext{
${ }^{21}$ Colectivo IOE (2008), Barometro Social de Espana, Analisis del periodo 1994-2006 a partir de un sistema de indicadores; p.171

${ }^{22} \mathrm{http}: / /$ barometrosocial.es/educacion

${ }^{23}$ Colectivo IOE (2008), Barometro Social de Espana, Analisis del periodo 1994-2006 a partir de un sistema de indicadores; p.181
}

Papeles de Europa

Vol. 27, Núm. 1 (2014): 105-136

http://dx.doi.org/10.5209/rev_PADE.2014.v27.n1.47014 
Culfaz, Eylul. El regimen del bienestar del Sur de Europa y los efectos de la crisis 2007 en el bienestar de España.

fundamentealmente al descenso de la renta per capita entre la población española y al aumento de la población juvenil que vuelve sus ojos al sistema educativo ante la falta de perspectivas laborales.

Grafico 9. La Evolución del Gasto en Educación en Relación al PIB en el periodo 1994-2010 (Base 100=1994)

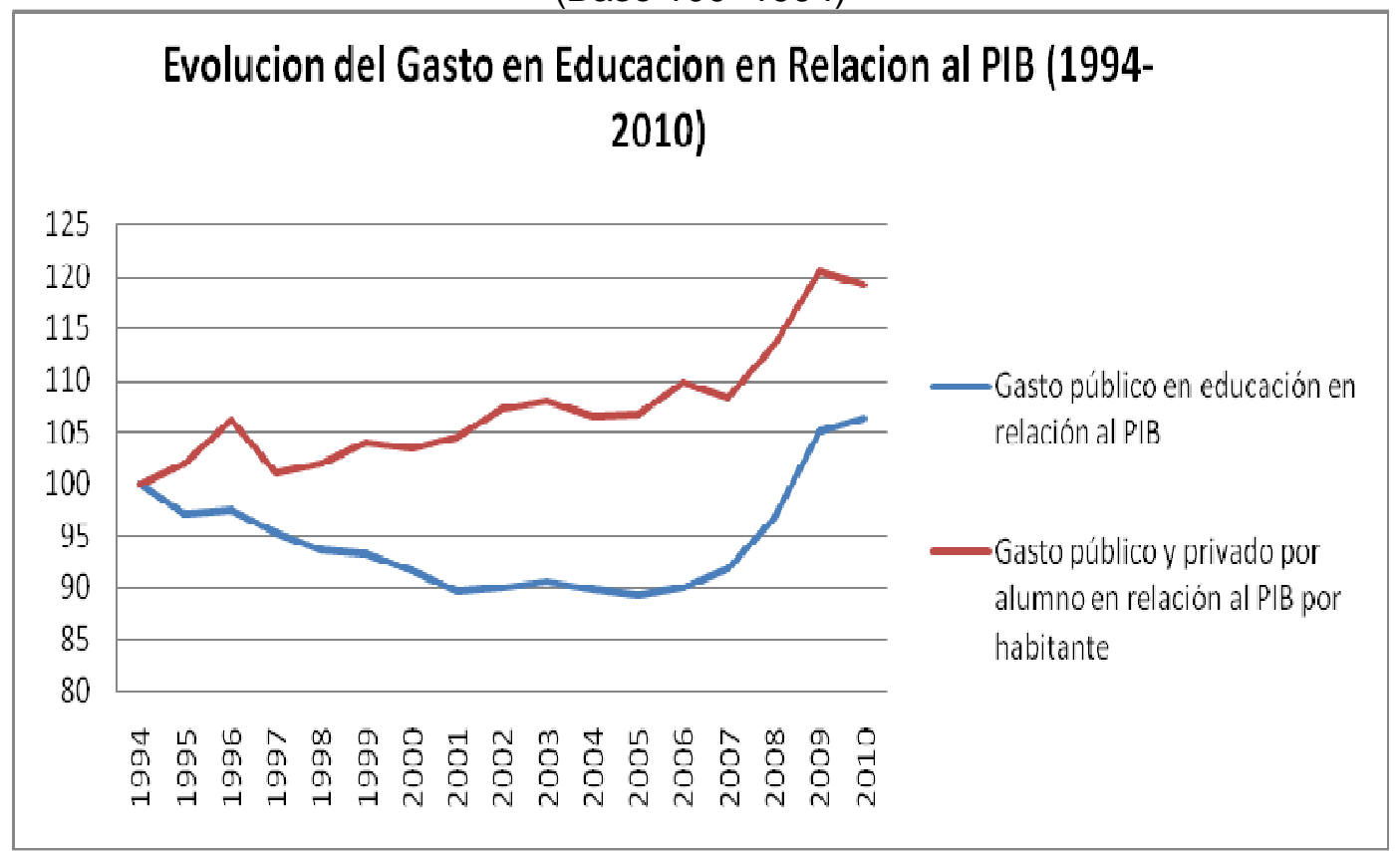

Fuente: www.barometrosocial.es

\subsection{Prestaciones de desempleo}

La tasa de paro empieza la última década con una tendencia decreciente, en buena medida herencia de la década previa en la que se asienta un modelo de crecimiento basado en el desarrollo de una burbuja financiero-inmobiliaria; con la crisis, y una vez que ha estallado la burbuja, el mercado laboral español se deteriora con gran celeridad, con unas magnitudes que no tienen precedentes. La tasa de paro empieza aumentar a partir de 2007, mucho más rápido que en otros países de Unión. La elevadísima tasa de paro de los jóvenes en los años 2008 y 2009 muestra que son la parte de sociedad más afectada por la crisis. ${ }^{24}$

Por otro lado, una buena parte de la población activa que no está en paro, está trabajando con contrato temporal. Al mismo tiempo, la crisis afectó a los salarios, perdiendo este poder adquisitivo; mirando la tasa anual del salario medio en España en euros constantes, para 2007 el dato muestra 4,4\% y tres años después se cambio por $-1,6 \%$. No es extraño que la crisis haya cambiado las cifras de pobreza. Según los datos de Encuesta de Condiciones de Vida del INE, el 21,8\% de la población vive por debajo de la brecha de pobreza ${ }^{25}$.

\footnotetext{
${ }^{24}$ La oficina estadistica de la UE situa a Espana a la cabeza del paro en Europa, con un 23,6\% de la poblacion activa desempleada y con un paro juvenil que, desde el mes febrero del 2008, ya supera el $50 \%$.

${ }^{25}$ INE se utiliza la nocion de pobreza relativa; es pobre quien tiene una renta menor al $60 \%$ de la renta del hogar mediano ( el hogar para el que la mitad de los hogares son mas ricos y la otra mitad de los hogares son mas pobres). Segun esta definicion, para una familia compuesta por dos adultos ser pobre significa en el ano 2011disponer de ingresos anuales inferiores a los 11.300 euros.
} 
Culfaz, Eylul. El regimen del bienestar del Sur de Europa y los efectos de la crisis 2007 en el bienestar de España.

La situación afecta a las prestaciones por desempleo también; particularmente, a la tasa de cobertura en relación con los parados. Por otro lado, la distribución de las prestaciones según las diferentes modalidades también muestra variaciones durante el periodo. El número total de parados se ha incrementado drásticamente a partir del año 2007, hasta alcanzar las elevadísimas tasas de desempleo de principios de la década de los noventa del siglo anterior. Si dividimos este número total de parados entre parados cubiertos con prestaciones contributivas y no, podemos ver que la parte no cubierta tiene una proporción mayor. Sin embargo, si miramos a la evolución de la proporción de los parados cubiertos en relación con el número total de parados, hasta 2008 había una tendencia creciente pero en últimos cuatro años volvió otra vez a los niveles de los años 90 s. Como podemos ver abajo, en el grafico 7 , en 1994, el porcentaje de los parados sin cobertura de prestaciones contributivas era del $80 \%$ y el porcentaje llegó a bajar hasta el 57,5 \% en 2008. En 2011, con un $72 \%$, se vuelve otra vez a los altos porcentajes de años anteriores. En resumen, a partir de la crisis, la proporción parados no cubiertos en relación al número total de parados empieza a aumentar otra vez, bajando el nivel del bienestar de la sociedad.

Grafico 10. La tasa de ocupación laboral de la población entre 15-64 anos en España y en UE 27, la tasa de paro en España y en UE y la tasa de paro de los jóvenes

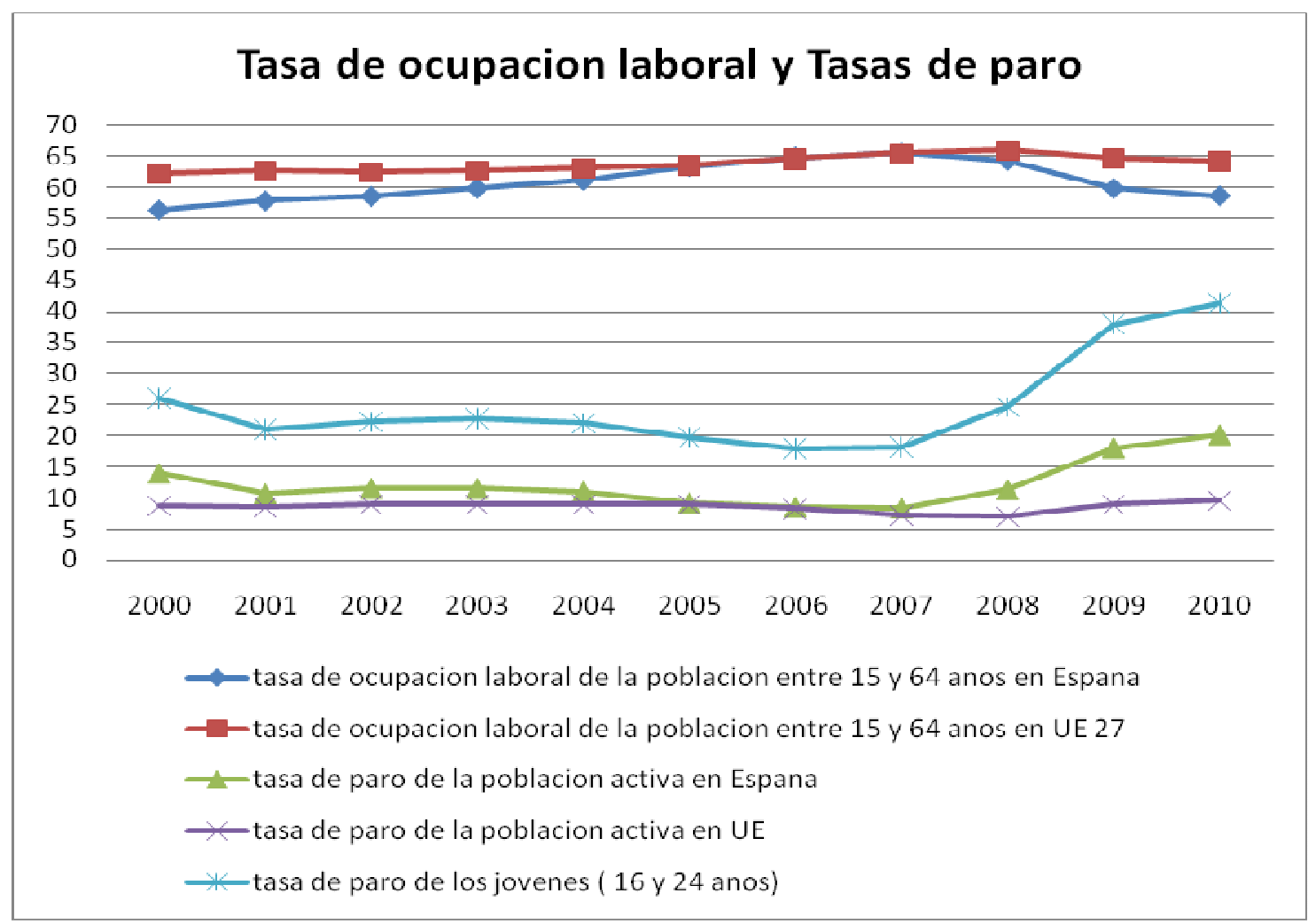

Fuente: www.barometrosocial.es

Desde el punto de vista de la distribución de las prestaciones por desempleo (grafico 12), las prestaciones contributivas también muestran la misma evolución, mientras que los subsidios asistenciales y eventuales agrarios tiene una tendencia contraria. El número de gente que recibe este tipo de las prestaciones aumenta, particularmente a partir del periodo de crisis. Rentas activas de insercion «que se otorgan desde el año 2000 a desempleados mayores de 45 años, emigrantes retornados, personas con discapacidades y víctimas de violencia de género con el 
Culfaz, Eylul. El regimen del bienestar del Sur de Europa y los efectos de la crisis 2007 en el bienestar de España.

fin de incrementar sus oportunidades de acceso al empleo» ${ }^{26}$ tambien se incrementan a un ritmo significativo.

Grafico 11. Parados no cubiertos con las prestaciones contributivas por el número total de los parados (\%)

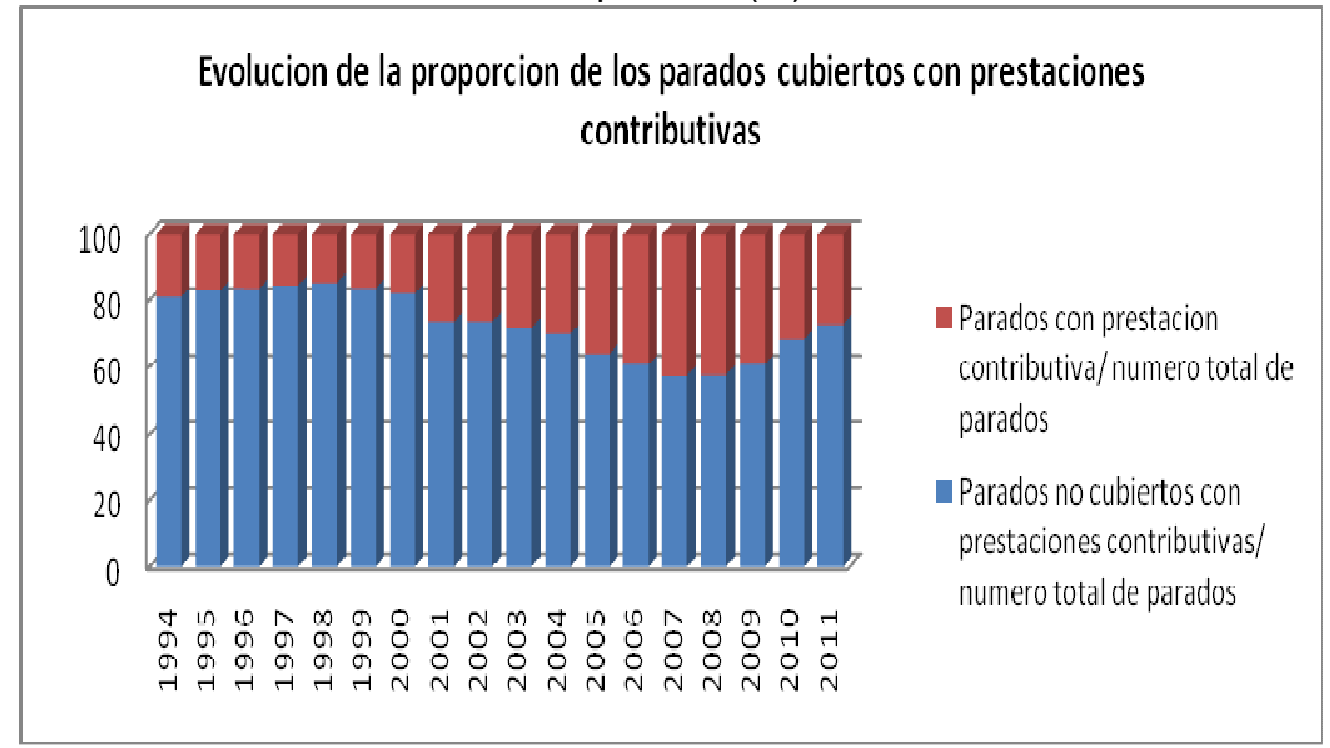

Fuente: www.barometrosocial.es y propios calculos.

Grafico 12. La Evolucion de las Prestaciones de Desempleo

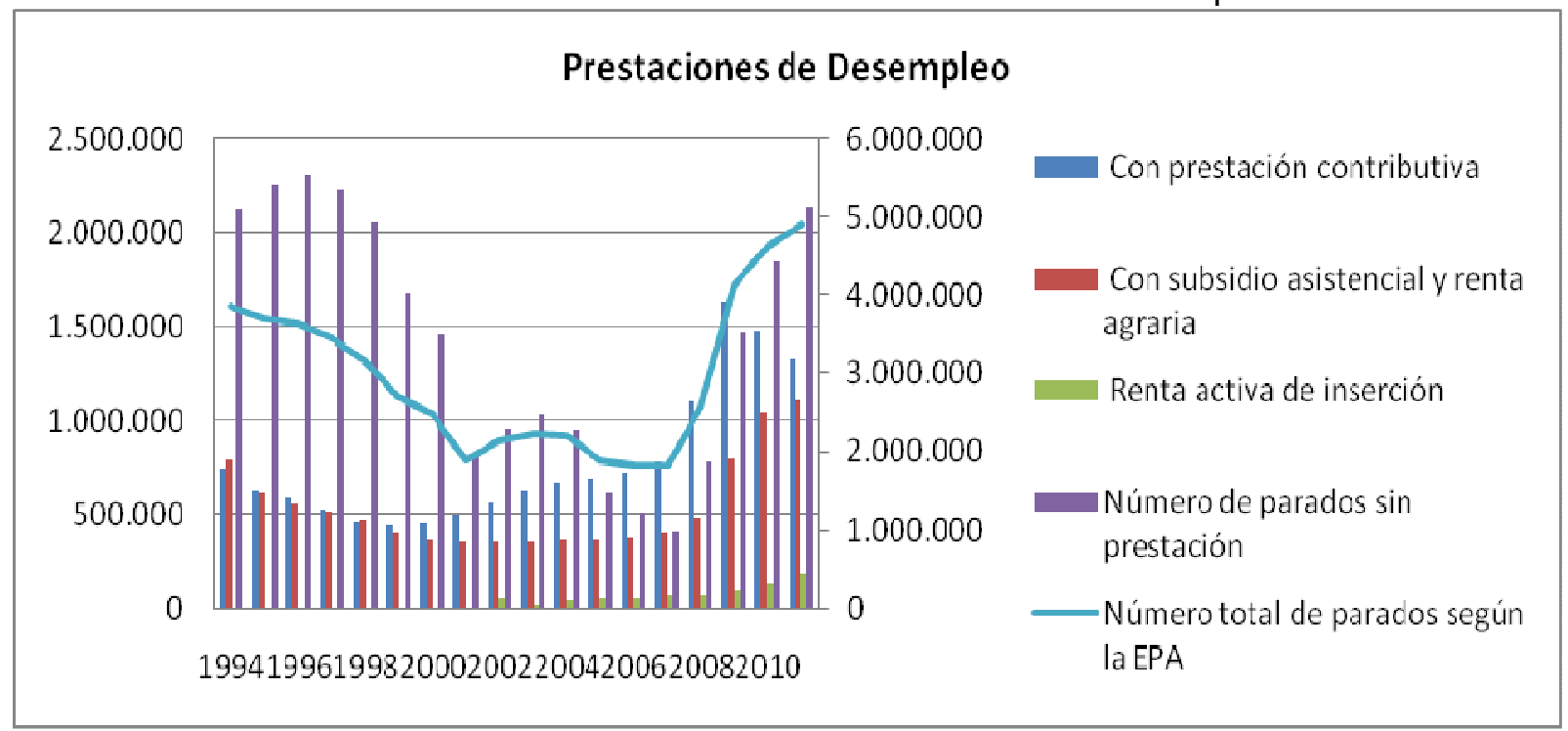

Fuente: www.barometrosocial.es

Por ser España un país con grandes problemas de desempleo, particularmente para los jóvenes, hay que mencionar también la distribución de las prestaciones por edad. Siendo los jóvenes quienes están sufriendo en mayor medida el desempleo, el grupo de 20-24 años es el grupo de edad de beneficiaros de prestaciones de desempleo con un porcentaje más bajo ${ }^{27}$. La mayoría de los trabajadores jóvenes

\footnotetext{
${ }^{26}$ Colectivo IOE; Barometro Social de Espana, Analisis del periodo 1994-2006 a partir de un sistema de indicadores; p.223.

${ }^{27} \mathrm{http} / / /$ barometrosocial.es/proteccion-social
}

Papeles de Europa

Vol. 27, Núm. 1 (2014): 105-136 http://dx.doi.org/10.5209/rev_PADE.2014.v27.n1.47014 
Culfaz, Eylul. El regimen del bienestar del Sur de Europa y los efectos de la crisis 2007 en el bienestar de España.

desempleados no están cubiertos por dichas prestaciones debido a que nunca han tenido la oportunidad de trabajar. Las familias se hacen cargo de los desempleados jóvenes, constituyéndose así en un pilar básico del régimen de protección y de generación de bienestar en la sociedad española.

\section{CONCLUSIONES}

Los debates iniciados en la década de los noventa del siglo pasado a partir de la tipología de Andersen sobre la existencia de un cuarto modelo de bienestar que incluya a los países mediterráneos de Europa (particularmente España, Italia, Grecia y Portugal) han servido de punto de partida de este trabajo de investigación. Dichos países, por tener características comunes en el mercado laboral, en la formación y en la estructura del estado de bienestar y en la sociedad civil, especialmente en el papel que desempeña de cara al bienestar social las familias, pueden ser considerados partícipes de un modelo específico de bienestar. Esta percepción del modelo de bienestar de los países del sur de Europa choca con la de aquellos que sostienen que la variante meridional se debe contemplar como una versión infra desarrollada, rudimentaria o residual de otros regímenes de bienestar.

En este trabajo he elegido a España como el país objeto de estudio que permita contrastar la existencia de un cuarto modelo específico que caracterice el bienestar de los países del sur de Europa. En el capítulo II, se presentan las características comunes del grupo de los cuatro países del Sur. Considerando los rasgos políticos, sociales y económicos, podemos decir que Italia, España, Grecia y Portugal comparten el mismo proceso del desarrollo capitalista, por ser países de industrialización tardía. La regulación del mercado laboral en dichos países es sensible particularmente a los riesgos sociales del primer orden. Por otro lado, hay una similitud en la evolución del gasto público en materia social y en su distribución, particularmente en las partidas destinadas al desempleo y vejez. Por último, el importante papel que desempeñan las familias para equilibrar el bienestar de la sociedad entre las esferas del mercado y el estado es una razón adicional para considerar a estos cuatro países como partícipes de un cuarto modelo.

Por último, la crisis económica que se empieza a manifiesta a partir del año 2007 está afectando directamente a este régimen de bienestar del sur de Europa. En España, la crisis ha afectado al sector privado drásticamente, lo que traslada la responsabilidad de proveer bienestar al estado y a las familias. Inicialmente el incremento en el gasto público en materias sociales y un aumento de la participación del sector público en el sector de salud y en el de la educación reflejan esta situación. Por otro lado, el descenso en los ingresos de los hogares y una tasa de desempleo creciente está debilitando el papel de las familias como un actor importante en el régimen del bienestar, y pone de manifiesto la necesidad de que surja un actor equilibrarte. Mientras, los planes de recortes en el gasto público social que se ponen en vigor en España fuerzan un cambio en la estructura del régimen, influyendo especialmente en los servicios educativos y de salud, debilitando de esta manera su carácter universal. En resumen, un sector privado deteriorado por la crisis, un sector público restringido por los recortes y una sociedad formada por hogares empobrecidos en el contexto de una economía en franco retroceso, puede conducir a una profunda quiebra en el modelo de bienestar vigente hasta ahora. 
Culfaz, Eylul. El regimen del bienestar del Sur de Europa y los efectos de la crisis 2007 en el bienestar de España.

Esta quiebra en el régimen de bienestar permite plantear preguntas para futuras investigaciones, ¿se está abriendo con esta quiebra la puerta a una profunda redefinición del modelo de bienestar en los países del sur de Europa o es posible todavía pensar que este cuarto modelo que incluye a dichos países aún pervivirá en el tiempo? 
Culfaz, Eylul. El regimen del bienestar del Sur de Europa y los efectos de la crisis 2007 en el bienestar de España.

\section{REFERENCIAS}

CASTLES, F. (1993): Family of Nations.Patterns of Public Policy, Oxford University Press, New York.

COLECTIVO IOE (2008): Barometro Social de Espana, Analisis del periodo 19942006 a partir de un sistema de indicadores, Centro de Investigación para la Paz, Madrid.

COLECTIVO IOE (2012): Crece la Desigualdad en España, Centro de Investigación para la Paz, Madrid.

CRUZ ROCHE, I. (1994): "La dinámica y estructura de la universalización de las pensiones". V Informe Sociológico sobre la Situación Social en España, Fundación FOESSA,1495-1505.

ESPING-ANDERSEN, G. (1990): Three Worlds of Welfare Capitalism, Princeton University Press, New Jersey.

ESPING-ANDERSEN, G. (1999): Social Foundations of Postindustrial Economies, Oxford University Press, Oxford.

EUROSTAT STATISTICS (2001): Population and Social Conditions, Statistics in Focus 17, por Puglia Antonella.

EUROPEAN COMMISSION (2007): Undeclared Work in the European Union, Special Eurobarometer 284. http://ec.europa.eu/public_opinion/archives/ebs/ebs_284_en.pdf

FERRERA, M (1995): "Los Estados del Bienestar del Sur en la Europa Social". en SARASA, S. and MORENO, L. (ed): El Estado del Bienestar en la Europea del Sur, pp. 85-111.

FERRERA, M. (1996): "The Southern Model of Welfare in Social Europe". Journal of European Social Policy, 6 (1),17-37.

FLAQUER, L. (1995): "El Modelo de Familia Española en el Contexto Europeo". en SARASA, S. And MORENO, L. (ed): El Estado del Bienestar en la Europa del Sur, pp. 261-288.

FLAQUER, L. (2000): Family Policy and Welfare State in Southern Europe, Institut de Ciencies Politiques i Socials, Universitat Autonoma de Barcelona, Barcelona.

GALLIE, D. y PAUGAM, S. (2000): The Social Regulation of Unemployment, Welfare Regimes and the Experience of Unemployment in Europe, Oxford University Press, Oxford.

GALLO de PUELLES, P. (1994): "Políticas de Recursos y Descentralización". V Informe Sociológico sobre la Situación Social en España, Fundación FOESSA, 861-874.

GOUGH, I. (1996): "Social Assistance in Southern Europe". South European Society and Politics, 1 (1), 1-23.

GUERRERO, T.J. y NALDINI, M. (1997): "Is the South so Different? Italian and Spanish Families in Comparative Perspective", en RHODES, M. (ed): Southern European Welfare States Between Crisis and Reform, 42-66.

KARAMESSINI, M. (2007): "The Southern European Social Model: Changes and Continuities in Recent Decades," Geneva: International Institute for Labor Studies, Discussion Paper Series, No.174.

KORPI, W. (1980): "Social Policy and Distributional Conflict in the Capitalist Democracies: A Preliminary Comparative Framework", European Politics, 3(3): 296-316. 
Culfaz, Eylul. El regimen del bienestar del Sur de Europa y los efectos de la crisis 2007 en el bienestar de España.

KUHNLE, S. (1997): "La Reconstrucción Política de los Estados del Bienestar Europeo", en MORENO, L. (ed.): Unión Europea y Estado del Bienestar, pp. 3165.

LE GRAND, J. (1982): "The Strategy of Equality. Redistribution and the Social Services". London: George Allen \& Unwin.

LEIBFRIED, S. (1992): "Towards a European Welfare State? On Integrating Poverty Regimes into the European Community". En FERGE, Z; KOLBERG, J (ed): Social Policy in a Changing Europe. Boulder, CO, 245-279.

LEWIS, J. (1989): "Lone Parent Families: Politics and Economics". Journal of European Social Policy Vol.2 (3): 159-173.

MINISTERIO DE EMPLEO y SEGURIDAD SOCIAL (2012): "Analisis del Contexto" en Estrategia de Emprendimiento y Empleo Joven. p: 38-52. http://www.empleo.gob.es/es/estrategia-empleo-joven/archivos/Analisis_de_

Contexto.pdf

MORENO, L. (1998): "Safety Net in Southern Europe"; 2nd International Research Conference on Social Security, Jerusalem. Instituto de Estudios Sociales Avanzados.

MORENO, L. (2001): "La Vía Media Española del Modelo de Bienestar Mediterráneo". Consejo Superior de Investigaciones Científicas, Papers 63/64, 67-82.

MORENO, L. (2004): "The Spanish Development of Southern Welfare". Working Paper 97-04. Madrid: CSIC.

PORRAS, M. y CASTELLANOS, J. L. (2002): "Los Servicios Sociales: Generales y Especializados. Su Importancia en las Politicas de Inclusion", en RODRIGUEZ CABRERO, G. y SOTELSEK, D. (eds): Apuntes sobre bienestar social, Madrid: Universidad de Alcala.

PZEWORSKI, A. (1985): "Capitalism and Social Democracy". Cambridge: Cambridge University Press.

RODRIGUEZ-CABRERO, G. (1994): "La Política Social en España: 1980-92”. V Informe Sociológico sobre la Situación Social en España, Fundación FOESSA, 1443-1494

SARACENO, C. (1995): "Familismo ambivalente y clientelismo categórico en el Estado del Bienestar Italiano", en SARASA, S. y MORENO, L. (ed.): El Estado del Bienestar en la Europa del Sur; 261-288.

SARASA, S. (1997): "El Tercer Sector en Transición", en MORENO L. (ed.), Unión Europea y Estado del Bienestar, 345-372.

SÖDERSTRÖM, L. (1988): "The Redistribution Effects of Social Protection: Sweden". en JALLADE, J. P. (ed.): The Crisis of Redistribution in European Welfare States.

TRIFILETTI, R. (1995): "Family Obligations in Italy". en MILLAR, J. y WARMAN, A. (ed): Defining Family Obligations in Europe, Bath Social Policy Papers No.23. Bath: University of Bath.

TRIFILETTI, R. (1999): "Southern European Welfare Regimes and The Worsening Position of Women". Journal of European Social Policy Vol.9 (1):49-64. 